\title{
Rodent Preclinical Models for Developing Novel Antiarthritic Molecules: Comparative Biology and Preferred Methods for Evaluating Efficacy
}

\author{
Brad Bolon, ${ }^{1,2}$ Marina Stolina, ${ }^{3}$ Caroline King, ${ }^{4,5}$ Scot Middleton, ${ }^{3}$ Jill Gasser, ${ }^{4,6}$ \\ Debra Zack, ${ }^{4,7}$ and Ulrich Feige ${ }^{4,8}$
}

${ }^{1}$ Department of Pathology, Amgen Inc., Thousand Oaks, CA 91320, USA

${ }^{2}$ GEMpath Inc., 2867 Humboldt Cir, Longmont, CO 80503, USA

${ }^{3}$ Department of Metabolic Disorders, Amgen Inc., Thousand Oaks, CA 91320, USA

${ }^{4}$ Department of Inflammation, Amgen Inc., Thousand Oaks, CA 91320, USA

${ }^{5}$ Willamette Health Partners, Salem, OR 97301, USA

${ }^{6}$ HAMILTON Bonaduz AG, 7402 Bonaduz, Switzerland

${ }^{7}$ Department of Global Development, Amgen Inc., Thousand Oaks, CA 91320, USA

${ }^{8}$ EUROCBI GmbH, Benglen, 8121 Zurich, Switzerland

Correspondence should be addressed to Brad Bolon, brad@gempath.net

Received 10 September 2010; Accepted 20 October 2010

Academic Editor: Oreste Gualillo

Copyright ( 2011 Brad Bolon et al. This is an open access article distributed under the Creative Commons Attribution License, which permits unrestricted use, distribution, and reproduction in any medium, provided the original work is properly cited.

Rodent models of immune-mediated arthritis (RMIA) are the conventional approach to evaluating mechanisms of inflammatory joint disease and the comparative efficacy of antiarthritic agents. Rat adjuvant-induced (AIA), collagen-induced (CIA), and streptococcal cell wall-induced (SCW) arthritides are preferred models of the joint pathology that occurs in human rheumatoid arthritis (RA). Lesions of AIA are most severe and consistent; structural and immunological changes of CIA best resemble RA. Lesion extent and severity in RMIA depends on experimental methodology (inciting agent, adjuvant, etc.) and individual physiologic parameters (age, genetics, hormonal status, etc.). The effectiveness of antiarthritic molecules varies with the agent, therapeutic regimen, and choice of RMIA. All RMIA are driven by overactivity of proinflammatory pathways, but the dominant molecules differ among the models. Hence, as with the human clinical experience, the efficacy of various antiarthritic molecules differs among RMIA, especially when the agent is a specific cytokine inhibitor.

\section{Introduction}

Imbalances in proinflammatory and anti-inflammatory immunomodulatory pathways can promote autoimmune responses that manifest as chronic inflammatory conditions. Diarthrodial joints (those with cartilage-capped surfaces, an intervening space filled with viscous fluid, and a synoviumlined capsule) are one major target of autoimmune attack. The classic immune-mediated joint disease in humans is rheumatoid arthritis (RA). The impact of this ailment on both individuals and society at large is immense. The estimated worldwide prevalence of RA is $1 \%$ to $2 \%$. Relative to healthy individuals, RA patients have three times greater direct healthcare costs and are also two times more likely to require hospitalization and ten times more likely to be disabled $[1,2]$.

The exact etiology (cause) and pathogenesis (mechanisms) of autoimmune joint diseases are uncertain. Current thinking is that the primary arthropathic immunological defects may include constitutive activation of immune surveillance cells [3] resulting in persistent relative overproduction of proinflammatory [4-7] and proerosive [810] cytokines and abnormal recognition of self-antigens as nonself due to their similarity with a foreign protein [3, 11-13]. The nature of the immunoregulatory disturbance differs among individuals, a fact indicated by the divergent 
responses of RA patients to cytokine-specific biopharmaceutical inhibitors $[7,14]$. Thus, RA is actually a syndrome in which a common set of structural changes is provoked by one or more of several cellular/molecular aberrations. Multiple factors including age, gender (hormonal status), genetic background, and environmental conditions influence the molecular events that regulate the onset and persistence of RA in people [15].

\section{Objectives of the Review}

Various rodent models of immune-mediated arthritis (RMIA) have become the standard means of evaluating hypothetical mechanisms of immune-mediated joint disease and for testing the comparative efficacy of novel antiarthritic drug candidates during preclinical development [16, 17]. The current paper has multiple objectives. First, available RMIA options will be listed and their features briefly summarized. Second, the biological attributes of major RMIA will be compared. Third, a subset of these RMIA will be recommended as the most appropriate surrogates for human RA and a rationale given for this selection. Fourth, procedures for the reliable production and assessment of the recommended RMIA will be described. Finally, practical principles that must be considered during RMIA selection and experimental design during preclinical drug development will be defined. The larger joint size in nonrodent models such as rabbits [18-20] or nonhuman primates $[21,22]$ may be the more appropriate model for preclinical investigation for some purposes. Nonetheless, this paper does not address analysis of immune-mediated joint disease in nonrodent models because they are used less commonly than RMIA [16].

\section{Objective 1: Available Rodent Models of Immune-Mediated Arthritis (RMIA)}

Many RMIA have been evaluated during the past five decades as potential models for evaluating immune-mediated joint injury. Some are suitable chiefly for evaluating cellular and molecular mechanisms of disease, while others may be employed to investigate both arthritis mechanisms and antiarthritic efficacy. The available RMIA options may be categorized in several fashions, including by affected species (rat, mouse, and guinea pig), disease type (genetically engineered, induced, or spontaneous), and inciting agent (e.g., chemicals, collagen, or exogenous polysaccharides/proteins/proteoglycans). This section uses all these classification schemes to provide a brief overview of possible and preferred RMIA.

3.1. Rodent Species Employed in RMIA Experiments. Rats and mice are the most common RMIA used for contemporary arthritis investigation [16] and are the focus of the current review. Guinea pigs are employed occasionally in immunemediated arthritis research, primarily to explore basic mechanisms [18, 23-26].
Rodents offer many advantages as research subjects for arthritis studies. First, their inexpensiveness, small size, and receptiveness to group housing substantially reduce research costs relative to studies in nonrodents. Second, many different rodent stocks and inbred strains may be used to assess the impact of biological heterogeneity on arthritis progression. Rodent strain-specific [27, 28] and even substrain-specific [29] genetic attributes as well as divergent immunological capacities [30, 31] can modulate the extent and severity of immune-mediated diseases; importantly, an analysis of conserved chromosomal homology among rats, mice, and humans suggests that arthritis susceptibility loci are highly conserved across these species [27, 28, 32]. Third, modern techniques allow deliberate alteration of the rodent genome to evaluate molecular mechanisms that regulate immunemediated joint disease (e.g., [33-36]). Fourth, procedures for initiating and evaluating RMIA have been well characterized and may be undertaken with inexpensive laboratory equipment (see below). Fifth, as mice (and rats) are the main species used for immunological research, numerous complementary reagents (e.g., cytokines and anticytokine antibodies) are readily available for these two species. Finally, the animal models of RA with a well-proven track record for predicting whether or not novel antiarthritic agents might be useful in human patients are all performed in rodents $[16,37]$. The closest resemblance to RA among the induced RMIA is the joint lesions in collagen-induced arthritis (CIA) $[38,39]$.

For each rodent species, susceptibility to immunemediated arthritis is limited to certain strains and stocks. For rats, the inbred DA and Lewis strains are susceptible to arthritis induction (Figure 1), while the inbred BN and F344 (Fisher) strains are relatively resistant [27]. Arthritissensitive mice include B10.Q, B10.RIII, and DBA/1 inbred strains $[40,41]$. Susceptible rodent strains are not equally vulnerable to all arthritogenic agents. For example, the DA rat develops AIA after one subcutaneous injection of incomplete Freund's adjuvant (IFA), while other rat strains are not sensitive to this very weak agent [42]. Furthermore, even within the sensitive DA rat strain, arthritis susceptibility is not uniform, as different substrains exhibit varying propensities for developing common induced forms of immunemediated arthritis [29]. The same genetic manipulation may produce polyarthritis in one strain without causing lesions in another; an example is the genetically engineered null mutation in interleukin-1 receptor antagonist (IL-1ra), where the knockout genotype yields a clinically prominent arthritis phenotype in BALB/c mice but does not affect C57BL/6 mice [33]. Arthritis is more severe and prolonged if the inciting agent is a self-antigen, such as mouse type II collagen, rather than an exogenous arthritogen $[42,43]$. These distinctions indicate that the suitability of each RMIA should be reestablished each time it is imported into a new research facility and again on each occasion when the animal supplier is changed.

3.2. Available Options for Investigating Immune-Mediated Arthritis in Rodents. Three broad classes of RMIA may be used to evaluate disease mechanisms and/or the potential 


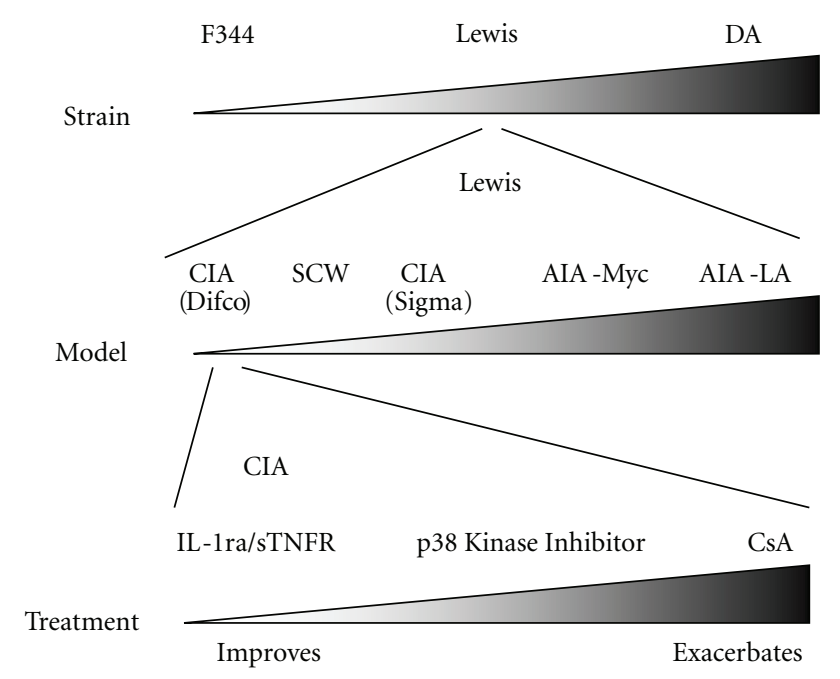

Figure 1: The ability to model immune-mediated disease is affected by many factors, including the animal strain (top triangle), the choice of model (middle triangle), and the nature of the antiarthritic molecules being tested (bottom triangle). For rat strains, susceptibility to arthritis is highest in DA and lowest in F344 animals. For rat model systems, the adjuvant-induced arthritis (AIA) variants are more aggressive than are the collageninduced arthritis (CIA) and streptococcal cell wall (SCW) versions; furthermore, the extent of AIA lesions depends on the inciting agent (lipoidal amine (LA) versus heat-killed Mycobacterium (Myc)), while the severity of the CIA lesions is more extensive if the source of incomplete Freund's adjuvant (IFA) is Sigma Chemical Co. (St. Louis, MO) rather than Difco Laboratories (Detroit, MI). With regard to treating rats with CIA, the greatest improvement in joint disease is achieved using the cytokine-inhibiting biologics interleukin-1 (IL-1) receptor antagonist (IL-1ra) and soluble tumor necrosis factor (TNF) receptor (sTNFR) and intermediate using small molecule blockers of p38 kinase (which regulates IL-1 and TNF). Depending on the treatment window, cyclosporin A (CsA) will inhibit, delay, or even exacerbate arthritis in Lewis rat CIA (compare also to Figure 8).

efficacy of novel antiarthritic molecules. These categories are induced, genetically engineered, and spontaneous disease. In general, mechanistic studies may be undertaken using RMIA from any of these classes, while efficacy studies performed during preclinical drug development usually employ one or more induced models (sometimes supplemented with a wellchosen genetically engineered model).

Induced RMIA. These models result from administration of an exogenous material and can be separated into several categories depending on the type of insult [44, 45]. Many variants develop from injected molecules. The first option, adjuvant-induced arthritis (AIA), results from intradermal administration of various oil-based chemicals. The traditional example is administration of heatkilled Mycobacterium tuberculosis in IFA (AIA-Myc), but comparable lesions result from introduction of various chemicals in IFA including avridine, heptadecane, lipoidal amine, pristane, or squalene, or by injection of IFA alone $[46,47]$. Rats are susceptible to all these AIA models, while mice are resistant to classic AIA variants [48] except for pristane [27]. The second alternative, collagen-induced arthritis (CIA), is elicited reliably in both rats [39] and mice [49] by hyperimmunization with homologous or heterologous type II collagen in IFA. The third option is injection of bacterial cell wall peptidoglycan (polysaccharide) fragments $[50,51]$. The classic example is streptococcal cell wall-induced arthritis (SCW), although other entities like Lactobacillus or Mycoplasma cell wall fragments, $\beta$-glucan, and lipopolysaccharide are also arthritogenic $[47,52,53]$. The bacterial fragments may be injected locally (i.e., intraarticular) or systemically. Disease severity and progression in rats is greatest for AIA, intermediate for CIA, and least for SCW (Figure 1). Adaptations of AIA, CIA, and to a lesser extent SCW are the current workhorse RMIA for preclinical drug development [16] (Table 1).

Other induced RMIA are used less frequently for product registration but still have considerable value for investigating mechanistic questions. The fourth induced RMIA option is to administer an exogenous protein into the joint of an antigen-immunized animal to produce antigen-induced arthritis (AntIA). In this model, initial subcutaneous immunization induces antibody production, after which subsequent intra-articular introduction of the antigen attracts antibodies into the joint. Classic antigens for AntIA include bovine serum albumin, ovalbumin, horseradish peroxidase, and keyhole limpet hemocyanin [54-56]. Persistence within the synovium of many of these antigens, especially those with a cumulative positive charge [57], appears to be a major factor in the development of chronic synovitis. A fifth induced RMIA, antibody-induced arthritis (AbIA), arises following local (intra-articular) or systemic introduction of monoclonal antibodies (typically a multiagent cocktail) directed against type II collagen or other self antigens that are highly expressed in joints $[18,58-61]$. In this model, antibodies must enter the joint to encounter their antigen. These models typically present as a mild, acute lesion relative to the joint alterations produced by other inciting agents. A sixth alternative is to inject proinflammatory cytokines directly into a joint (usually the tibiotarsal joint (knee) due to its large volume) to induce an acute synovitis [62, $63]$. Interestingly, IL- $1 \beta$ and TNF- $\alpha$ produce distinct, timedependent patterns of acute arthritis in the rat knee following direct injection [62]. Thus, this RMIA has utility not only to investigate proinflammatory mechanisms but also as a means of predicting potential schedules, relative potencies, and comparative efficacies of various inhibitors of cytokine blockers.

Two other induced RMIA provoke subcutaneous lesions that serve as faux joints rather than immune-mediated disease of the rodent's own diarthroidal joints. The first variant involves surgical implantation of human joint tissuenormal or inflamed articular cartilage and/or synoviuminto SCID (severe combined immunodeficiency) mice [6466]. The second option is introduction of sterile air into the subcutis to initiate a pouch granuloma [67], the wall of which exhibits many similarities to synovium $[68,69]$. Subsequent injection of such molecules as carrageenan [70], $\gamma$-globulin [71], streptococcal cell wall fragments [72], or zymosan 
[73] incites an inflammatory response in the pouch that morphologically resembles acute and chronic synovitis [44]. Both xenografts and air pouches can be employed to evaluate the efficacy of therapeutic agents on synovitis and cartilage degeneration [73, 74]. Advantages of these two RMIA are their conceptual simplicity, their ability to incorporate tissue from normal and RA-affected human joints, and their large dimensions (relative to the size of rodent joints). However, their main disadvantages are that these subcutaneous sites do not recapitulate the normal joint structure (because they usually lack cartilage) and function (because they do not bear weight).

Genetically Engineered RMIA. These models have been deliberately constructed by gene targeting (mice only) or transgenic technology to overproduce, underexpress, or lack one or more immunoregulatory molecules (ligands or receptors) (Table 1). In most instances, engineered RMIA are generally used for basic experiments to explore proposed molecular mechanisms although they can be employed to evaluate the efficacy of therapeutic candidates designed to impact a particular immunoregulatory pathway [45]. Important transgenic mouse models of arthritis express human major histocompatibility complex (MHC) class II allele HLA-DR $[35,75,76]$ or overexpress proinflammatory cytokines like tumor necrosis factor- $\alpha(\mathrm{TNF} \alpha ;[34,77])$ or enzymes that degrade articular components (e.g., matrix metalloproteinases (MMP); [78]) or critical T lymphocyte receptors $[36,79]$. Other significant mouse arthritis models have been constructed to lack endogenous cytokine inhibitors such as IL-1ra [33, 80]. In some instances, engineered mouse models of arthritis carry two or more genetic alterations; a well-known example is the $\mathrm{K} / \mathrm{BxN}$ mouse, which expresses both a human $\mathrm{T}$-cell receptor transgene (designated KRN) and the human MHC class II molecule $A(g 7)[36,61]$. The principal genetically engineered rat arthritis model carries transgenes for both the human MHC class I allele HLA-B27 and human $\beta 2$-microglobulin [81, 82] and develops an immune-mediated joint disease which more closely resembles ankylosing spondylitis in humans rather than RA. Defective function of all these molecules has been linked in humans to RA and ankylosing spondylitis [7, 83-85]. Symmetrical polyarthritis in genetically engineered rodents develops at various times among the different models, with the span required for $100 \%$ penetrance ranging from 3 to 4 weeks of age in TNF $\alpha$-transgenic mice [77] to 13 weeks of age in IL-1ra knockout mice [33]. The hock (ankle) joints appear to be the earliest and most commonly targeted sites in most models although other regions such as the interphalangeal (toe) and coxofemoral (hip) joints are attacked as well or even preferentially in some models.

Spontaneous RMIA. Naturally occurring animal models with immune-mediated joint disease resembling human RA are rare (Table 1). The classic example is the MRL/Mpj-lpr/lpr (MRL/lpr) mouse, which develops a systemic autoimmune disease that includes joint involvement. Polyarthritis with pannus formation and cartilage degeneration primarily involving the hind limbs develops by five months of age in association with antibodies to type II collagen [86, 87]. Onset of the condition is associated with several immunoregulatory deficiencies including macrophage activation $[88,89]$ and altered production of various cytokines [90, 91].

\section{Objective 2: Comparative Biology of Rodent Models of Immune-Mediated Arthritis}

4.1. Morphologic Lesions in RMIA. All RMIA have pathologic features that are reminiscent to some degree of the typical lesions observed in the human RA joint. The RMIA resulting from systemic exposure to an arthritogen generally affect multiple joints and usually develop first in the hind paws [87, 92-94]. In contrast, targeted induction of RMIA by direct injection of an agent into a single joint usually yields a monoarticular disease $[6,41,62]$. Indeed, some researchers use the contralateral joint as an untreated control tissue although this practice is questionable since lesions also may be induced in the uninjected knee [20].

The structural appearance of affected joints in RMIA exhibits an overlapping spectrum of changes, the exact nature of which depends on both the inciting agent and the length of time over which arthritis has been allowed to progress. Findings may be classified using structural effects (inflammation, skeletal damage, and vascular changes) or temporal criteria (acute (early) and chronic (late) clinical stages). Acute lesions $[59,62,95]$ are characterized by substantial soft tissue edema, an extensive influx of neutrophils with lesser numbers of mononuclear leukocytes (chiefly lymphocytes and macrophages), abundant extravasation of fibrin, and modest synovial hyperplasia and skeletal erosion. Progression over time results in chronic lesions characterized by substantial synovial hyperplasia, production of fibrovascular tissue sheets (pannus) that extend from the synovium into the joint space, matrix degeneration in the articular cartilage, and extensive infiltration of perivascular soft tissues with a mixed inflammatory cell infiltrate in which lymphocytes, macrophages, and plasma cells predominate; neutrophils, fibrin, and soft tissue edema are understated if present at all in such established lesions $[8,93,94,96]$. Skeletal erosion begins one to two days after the paw swelling associated with acute synovitis develops [93, 94]. Left untreated, the extent of cartilage matrix degeneration (specifically proteoglycan loss in the articular surface [97]) and bone attrition increases rapidly over time $[8,93,94$, 98]. The widespread formation of osteophytes along the periosteal surface in some RMIA (AIA > CIA $\gg$ SCW) may eventually result in fusion (ankylosis) of the affected joints. The bone marrow, including that in the cores of osteophytes, in some RMIA (AIA $\gg$ CIA > SCW) contains myriad inflammatory cells and activated osteoclasts early during disease. However, over time both these cell populations regress to be replaced by fibrous connective tissue or fat [99]. Vascular proliferation in the synovium and periarticular soft tissues is a prominent component of some RMIA [100, 101].

Joint involvement varies among RMIA. For example, arthritis in AIA-Myc in Lewis rats reliably occurs early in the tibiotarsal and intertarsal joints (hock (or "ankle")) of the hind paws [102] and also in the femorotibial joints (knee) 
TABLE 1: Common rodent models of immune-mediated arthritis used in preclinical development of antiarthritic therapies.

\begin{tabular}{|c|c|c|c|c|}
\hline Categories & Induction principle & Examples & Inciting agents/genetic alteration & Species \\
\hline \multirow{5}{*}{$\begin{array}{l}\text { Genetically } \\
\text { engineered }\end{array}$} & \multirow{5}{*}{$\begin{array}{l}\text { Deliberate manipulation of one or more } \\
\text { genes encoding proteins that regulate the } \\
\text { immune response }\end{array}$} & $\begin{array}{l}\text { HLA-B27 } \\
\text { transgenic }\end{array}$ & $\begin{array}{l}\text { Human leukocyte antigen (HLA) B27 (a major } \\
\text { histocompatibility complex (MHC) class } 1 \\
\text { molecule) and human } \beta 2 \text {-microglobulin }\end{array}$ & Rat \\
\hline & & $\begin{array}{l}\text { HLA-DR } \\
\text { transgenic }\end{array}$ & $\begin{array}{l}\text { Human leukocyte antigen, D-related (a MHC } \\
\text { class II molecule) }\end{array}$ & Mouse \\
\hline & & IL-1ra knockout & Interleukin-1 receptor antagonist & Mouse \\
\hline & & $\mathrm{K} / \mathrm{BxN}$ & $\begin{array}{l}\text { Human T-cell receptor (KRN) and a human } \\
\text { MHC class II molecule }\end{array}$ & Mouse \\
\hline & & TNF- $\alpha$ transgenic & Tumor necrosis factor- $\alpha$ & Mouse \\
\hline \multirow{5}{*}{ Induced } & \multirow{5}{*}{ Administration of an exogenous material } & \multirow{3}{*}{$\begin{array}{l}\text { Adjuvant-induced } \\
\text { arthritis (AIA) }\end{array}$} & Lipoidal amine & Rat \\
\hline & & & Mycobacterium tuberculosis & Rat \\
\hline & & & Pristane & $\begin{array}{l}\text { Mouse, } \\
\text { rat }\end{array}$ \\
\hline & & $\begin{array}{l}\text { Collagen-induced } \\
\text { arthritis (CIA) }\end{array}$ & Type II collagen (bovine, porcine, and rodent) & $\begin{array}{l}\text { Mouse, } \\
\text { rat }\end{array}$ \\
\hline & & $\begin{array}{l}\text { Bacterial cell } \\
\text { wall-induced } \\
\text { arthritis }\end{array}$ & $\begin{array}{l}\text { Bacterial cell wall peptidoglycan (polysaccharide): } \\
\text { Lactobacillus sp., Streptococcus sp. (SCW) }\end{array}$ & Rat \\
\hline Spontaneous & & MRL/lpr & MRL/Mpj-lpr/lpr & Mouse \\
\hline
\end{tabular}

(Figure 2) but does not develop in the forepaws until much later. Lesions in Lewis rats with AIA-LA are evident in the knee but not in the ankle (Figure 2) or forepaws. In contrast, joints of both the fore paws and the hind paws are involved in Lewis rats with CIA. The degree of hind paw swelling is much greater for both AIA models than it is for CIA (Figure 3) or SCW.

As in RA, immune-mediated polyarthritis in RMIA can have systemic consequences. Extra-articular structural changes observed in rat AIA include autoimmune reactions at other sites (e.g., blood vessels, brain, and uvea of the eye), bone loss in the axial skeleton, bone marrow hyperplasia (accompanied by multilineage leukocytosis), and reactive hyperplasia with enlargement of regional lymph nodes and spleen $[10,94,103]$. In contrast, the main extra-articular effects observed in rat CIA are concomitant bone loss in the axial skeleton [10] and reactive hyperplasia but not enlargement limited to the regional lymph nodes [93]. Significant systemic effects are not evident in rat SCW [104].

The pathologic presentation of RMIA differs distinctly from that of human RA in several critical respects [37]. First, rodents exhibit more prominent damage to the articular surface (full-thickness cartilage matrix degeneration with later cartilage dissolution; [8]) and adjacent bone (ranging from partial erosion to complete penetration of the original cortex accompanied by exuberant formation of periosteal osteophytes; $[8,94,105])$. These changes are evident even in those RMIA in which pannus is a less prominent element of the joint lesion (e.g., AIA-Myc, acute SCW). Another difference is the accelerated progression of joint damage in RMIA (days to a few weeks) relative to disease evolution in RA joints (months to years). Corollaries to this rapid advancement in RMIA are that the nature of the inflammatory changes at the time of peak joint damage is subacute (i.e., includes a greater influx of neutrophils and more edema) relative to RA, and that the severe destabilization of massively eroded joints in RMIA leads to early and extensive ankylosis, which is rarely seen in human adult RA. Finally, a much greater degree of osteoclast production is evident in affected joints in RMIA [102].

\subsection{Mechanisms That Regulate Joint Disease in Rodent Models of Immune-Mediated Arthritis}

4.2.1. Involvement of Cellular and Humoral Immunity. Initial onset of synovitis in RMIA results from innate immunity, but disease progression is a consequence of both cellmediated (Th1-type) and humoral (antibody-based, or Th2type) immune responses. The degree to which these systems regulate lesion evolution varies among models, but disease is most severe when both cellular and humoral branches are invoked [106]. Both innate immunity (via early infiltration by neutrophils and later production of macrophages) and acquired immunity (through expansion of sensitized Band T-lymphocyte lineages) are involved. The initial intraarticular driving force in induced RMIA appears to be deposition of exogenous antigens in synovial blood vessels [92] except for CIA, where the earliest event is thought to be production of anticollagen antibodies leading to immune complex deposition on and in the articular cartilage [41].

All RMIA as well as RA [107] are driven by cellmediated immunity, reflecting the activity of sensitized autoimmune T lymphocytes of the T-helper (Th) phenotype. This dependence is shown by the ability to pass rat AIA $[11,108,109]$ as well as rat [110] and mouse [111] CIA to nonimmunized (naive) recipients by transferring sensitized 


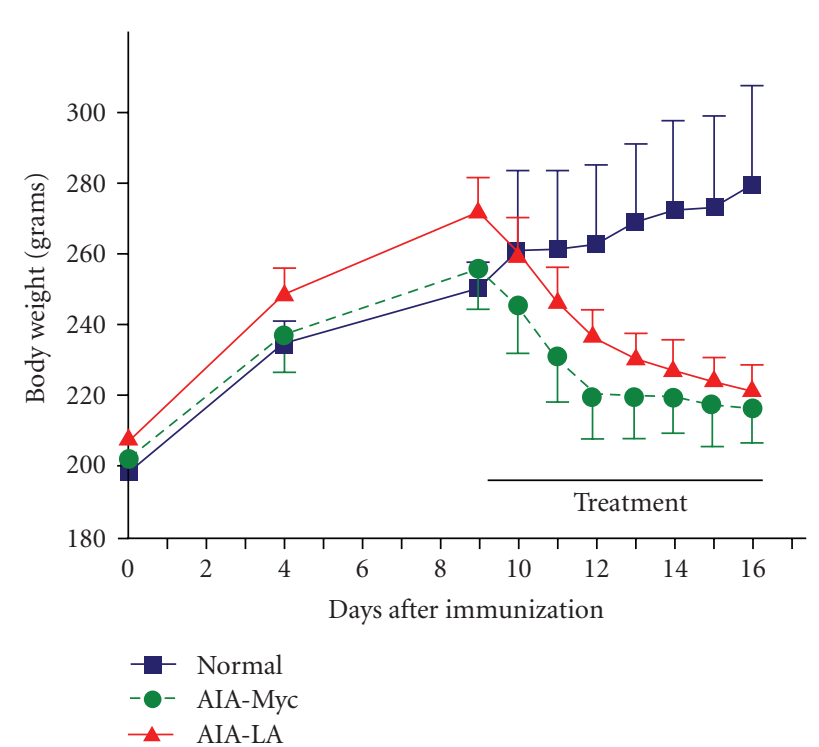

(a)

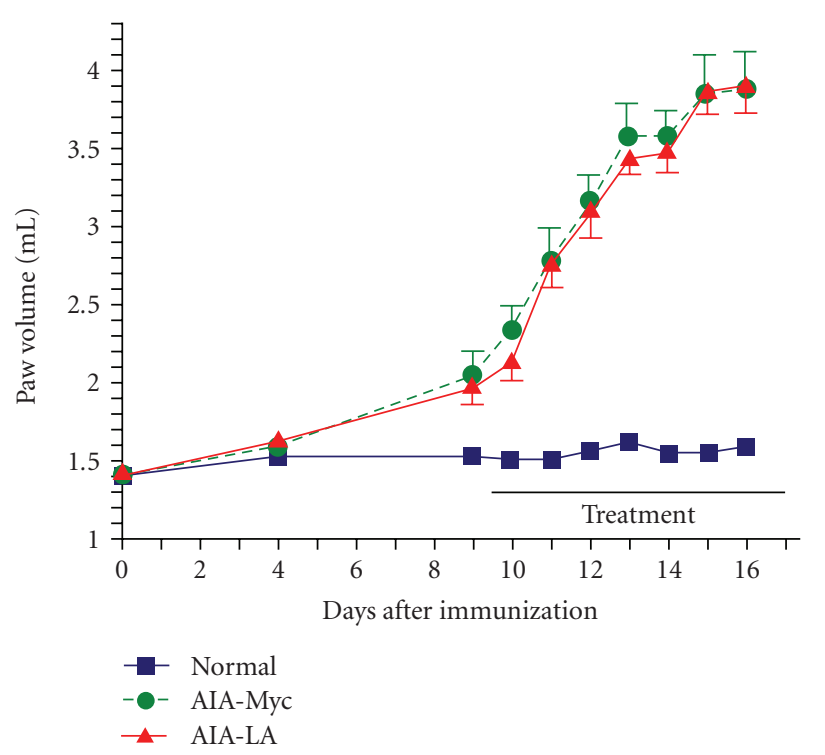

(b)

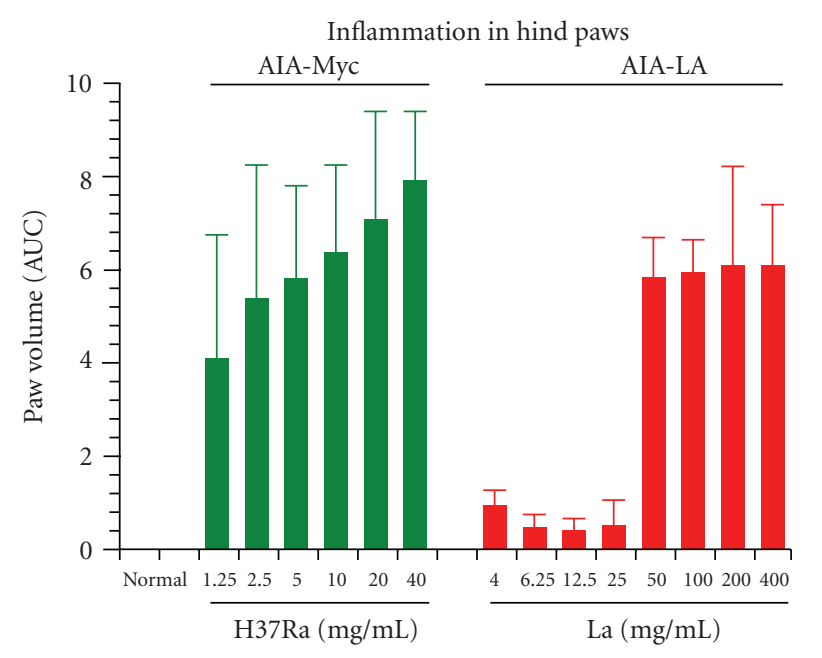

(d)

FIGURE 2: Related rodent models of immune-mediated arthritis (RMIA) will respond in similar or different manners, depending upon the parameter being assessed. Rat adjuvant-induced arthritis initiated with lipoidal amine (AIA-LA) or heat-killed Mycobacterium tuberculosis H37Ra (AIA-Myc) develops 9 days after adjuvant injection. Both models exhibit similar declines in total body weight (a), increases in hind paw volume (b), and reductions in bone mineral density (BMD) in the knee (femorotibial joint) (c). However, BMD in the ankle (tibiotarsal and intertarsal) joints is reduced only in AIA-Myc (c). Another difference between the two models is the nature of the dose-response curve for inducing arthritis (d); the proinflammatory response to Mycobacterium $\mathrm{H} 37 \mathrm{Ra}$ is linear across a broad dose range, while the response to lipoidal amine exhibits an abrupt threshold (at $50 \mathrm{mg} / \mathrm{mL}$ ) below which adjuvant injection does not produce disease. Both AIA models were induced in young adult (7- to 8-week-old), male Lewis rats. Lipoidal amine was given as a single intradermal injection of $5 \mathrm{mg}$ (in $0.1 \mathrm{~mL}$ of complete Freund's adjuvant; Difco Laboratories, Detroit, MI) at the tail base, while H37Ra was generated and administered as described in Section 6. Bars associated with data points represent standard error of the mean.

T-cells from affected donors and by the inability to induce AIA [27] or SCW [112] in athymic rats. A major function of the sensitized autoimmune cells is recognition of type II collagen as a substrate [113].

Humoral immunity resulting from B-lymphocyte activity and plasma cell proliferation is a feature of many RMIA and RA. Anticollagen antibodies are found in CIA $[114,115]$ and in some [116, 117] but not all [27] AIA variants, as well as in many RA patients $[118,119]$. Indeed, activity of B-lymphocytes is absolutely required for CIA induction as joint disease does not develop in B-cell-deficient mice [120]. Accumulation of immune complexes both in articular cartilage and in circulation is a common feature of many RMIA [87, 121, 122]. Introduction of anticollagen antibodies in the absence of sensitized lymphocytes can induce arthritis, although in the absence of T-helper cells to boost the immune response, the antibody-driven disease is transient and mild $[114,123]$; this outcome suggests that the role of 


\begin{tabular}{|c|c|}
\hline Model & Paw swelling $(\mathrm{mL})$ \\
\hline AIA-LA & $2.5-4$ \\
\hline AIA-Myc & $2.5-4$ \\
\hline CIA (IFA-Sigma) & $1-1.2$ \\
\hline CIA (IFA-Difco) & $0.4-0.6$ \\
\hline
\end{tabular}

Figure 3: The severity of immune-mediated joint disease in rats varies with the model and the choice of reagents. Adjuvant-induced arthritis induced in young adult, male Lewis rats using either lipodal amine (AIA-LA) or Mycobacterium tuberculosis (AIA-Myc) produces extreme swelling and reddening of the tibiotarsal region (hock (or "ankle")) (upper image) relative to the changes that develop in young adult, female Lewis rats with collagen-induced arthritis (CIA). The degree of hock expansion associated with CIA induction using incomplete Freund's adjuvant (IFA) from Sigma Chemical Co. (St. Louis, MO) (middle image) is greater than that associated with IFA provided by Difco Laboratories (Detroit, MI) (lower image). Intra-articular inoculation of streptococcal cell wall (SCW) polymers results in modest hind paw swelling (not shown).

humoral immunity in RMIA may be subsidiary to that played by the cell-mediated immune response. Antibodies to type II collagen are not observed in some RMIA, such as bacterial cell wall-induced arthritis [44], and the presence of such antibodies in RMIA does not automatically mean that they contribute significantly to joint destruction [27].

4.2.2. Cytokine Production in Rodent Models of ImmuneMediated Arthritis. The balance between cellular and humoral immunity in RMIA, as in RA, is attributed to variations in cytokine expression patterns in immunoregulatory cells, particularly T-helper (Th) lymphocytes. Autoimmune diseases have been postulated to be dependent on Th1 cells (which regulate cell-mediated processes marshaled to counter tumor cells and intracellular pathogens) more so than on Th2 cells (which generally drive humoral immune responses to vanquish extracellular organisms). Expression of Th1 versus Th2 cytokines in AIA changes over time and is subject to control by sensory innervation [124]. Overactivation of either Th pathway can cause disease, and either pathway can downregulate the other. Furthermore, other classes of Th cells have been described, some of which play a role in autoimmune arthritis (e.g., Th17 cells [125]). While the original Th1/Th2 hypothesis of immune control was developed in mice [126], the recent literature reveals that cytokine patterns in rodent and human diseases seldom follow an exclusive Th1-inducing or Th2-inducing pattern.

A complex web of chemokines and cytokines controls the immune response in joint tissue under normal circumstances. The balance between the functions of these molecules determines whether or not intra-articular inflammatory responses are transient and reparative or persistent and destructive. In general, immune-mediated joint disease results from overproduction of proinflammatory (e.g., IL1, IL-6, IL-17, and TNF- $\alpha$ ) and proerosive (e.g., receptor activator of $\mathrm{NF} \kappa \mathrm{B}$ ligand (RANKL)) factors, hyperactivity of proinflammatory and proerosive signaling pathways, or a reduction in cytokines (e.g., IL-4, IL-10, and transforming growth factor- $\beta$ (TGF- $\beta$ )) and soluble receptors (e.g., IL$1 \mathrm{ra}$, soluble TNF receptor (sTNFR)) that antagonize the proinflammatory response [127-129]. Abnormalities in the local (intra-articular and/or periarticular) or systemic (circulating) levels of such mediators have been reported in RA [130] and many RMIA, including AIA [94], CIA [93], and SCW [131].

The large number of mediators involved in regulating immune-mediated arthritis implies that one or a few molecules may serve as "master cytokines" [127], early expression of which is the main upstream incident that induces all other events needed to launch and sustain arthritis. The master proinflammatory cytokines which appear to drive immune-mediated joint disease in RA and RMIA are IL-1 (especially the inducible $\beta$ form) and TNF- $\alpha[132$ 135], possibly IL-6 [7], and perhaps others. A good indicator of a master cytokine in a distinct RMIA or human disease is superior antiarthritic efficacy by a cytokine inhibitor as exemplified for CIA (more IL-1 dependent) and AIA (more TNF dependent) [136]. However, although these master cytokines can act individually as arthritogens, they can also act together in synergistic fashion to potentiate joint inflammation; for example, IL-1 [4, 137] and IL-17 [138] exhibit synergistic activity with TNF- $\alpha$. Other cytokinessuch as IL-12, IL-15, IL-17, and IL-18 [139-141] —as well as chemokines, such as chemokine (C-C motif) ligand 2 (CCL2 [142]) and chemokine (C-X-C motif) ligand 8 (CXCL8 [143]), have also been implicated as additional participants in immune-mediated arthritis but are not thought to function as master cytokines, at least not in the immunemediated joint diseases studied thus far.

Alterations in the balance between pro- and antiinflammatory molecules occur locally and systemically in advance of the clinical onset of immune-mediated joint disease. In induced RMIA, such changes can be demonstrated by four days after inoculation of the arthritogen, which is between five to ten days prior to initial joint swelling [27, 93, 94]. Proinflammatory molecules required to initiate synovitis are upregulated earlier than proerosive mediators [93, 94]; this temporal sequence matches the evolution of structural changes within arthritic joints, where evidence of acute inflammation (edema, leukocyte infiltration, and fibrin extravasation) precedes visible damage to skeletal structures (osteoclast proliferation, cartilage matrix degeneration, and skeletal erosion). The increase in local and systemic chemokine and cytokine levels is accompanied by enhanced production of other molecules that enhance inflammation (e.g., cyclooxygenase- 2 and prostaglandin $\mathrm{E}_{2}$ $\left(\mathrm{PGE}_{2}\right)$ ), skeletal destruction (e.g., MMPs), and vascular expansion (e.g., platelet-derived growth factor and vascular endothelial growth factor) $[27,144]$. 
Despite some overlap in their cytokine signatures, different RMIA have divergent local and systemic proinflammatory profiles. For example, rats with AIA or CIA both produce enhanced levels of IL- $1 \alpha$, IL- $1 \beta$, and TGF- $\beta$ locally (inside inflamed joints) in conjunction with higher systemic levels of $\alpha 1$ acid glycoprotein, CCL2, and TGF- $\beta$ prior to arthritis onset, and both models also exhibit higher intraarticular amounts of CCL2, IL-6, PGE 2 , RANKL, and TGF$\beta$ with more circulating CCL2, IL- $1 \alpha$, IL- $1 \beta$, IL- 6 , and RANKL $[93,94]$. In contrast, prior to arthritis onset, the pro-arthritic signature of male Lewis rats with AIA includes no mediator enhancement that was unique to joints but did have systemic increases in CCL2, IL-17, TGF- $\beta$, and TNF- $\alpha$ [94], while female Lewis rats with CIA have locally higher levels of CCL2 and IL-18 with systemic elevation of CXCL1 (former designation: KC/GRO) [93]. After clinical arthritis becomes evident, male rats with AIA uniquely exhibit local enrichment for IL-17 and TGF- $\beta$ in conjunction with systemic increases in IL-17, IL-18, and TNF- $\alpha$ [94], whereas the distinctive profile in female rats with CIA includes local augmentation of IL-18 and CXCL1 with systemic amplification of IL-1 $\beta$ [93]. Thus, systemic and local processes in immune-mediated arthritis are discrete processes in Lewis rats, driven by multiple mediators with distinct spatiotemporal patterns of expression. Furthermore, the "master cytokine" hypothesis applies not only to events in the joint but also to immunological functions triggered throughout the individual. This latter premise is supported by the fact that the two major proinflammatory cytokines were confined to separate compartments in RMIA; IL-1 is restricted chiefly to arthritic joints, while TNF- $\alpha$ is limited mainly to the circulation $[93,94,128]$.

4.2.3. Hormonal Effects on Rodent Models of ImmuneMediated Arthritis. Both the hypothalamic-pituitarygonadal (HPG) axis and the hypothalamic-pituitaryadrenal (HPA) axis are instrumental in regulating immune responsiveness, and thus the susceptibility to immunemediated arthritis. Adrenal (glucocorticoids) and gonadal (androgens and estrogens) hormones act as natural immune suppressors, so a deficiency of one or more of these molecules permits enhanced immune reactivity. Females appear to rely more on the HPA axis while males seem to depend more on the HPG axis [145]. The lapse in immune control by deficiencies in certain hormonal axes particularly enhances cell-mediated (Th1-type) events [145].

The impact of gender on the sensitivity to immunemediated arthritis is readily apparent in the clinical setting. The incidence and severity of joint disease is higher in females for RA and most RMIA [27, 28]. Exceptions to this female bias are AbIA [59] and CIA [28] in mice and CIA in rats [146], where males may exhibit a higher incidence and develop more severe disease than do females. Administration of estradiol or castration of male rats results in a higher susceptibility to SCW [147].

Stress is a major factor in susceptibility to immunemediated joint disease. For example, SCW-susceptible Lewis rats have small adrenal glands and a markedly impaired ability to release corticotropin and corticosterone (products of the HPA axis) relative to SCW-resistant F344 animals [148]. The HPA axis is also a player in AIA in rats as well as CIA in rats and mice [146]. Persistent production of stress hormones (e.g., cortisol) and sympathetic system (emergency (fight or flight)) neurotransmitters, such as norepinephrine, boosts the baseline homeostatic state into a constant condition of relative proinflammatory readiness [149]. Despite this trend, the stress of handling has also been shown to reduce the sensitivity to CIA induction [150], indicating that due care must be exercised to maintain identical husbandry practices to avoid confounding hormonal fluctuations among treatment groups. A reasonable practice in some settings will be to include untreated controls as well to ensure that a profound stress-induced deviation in the vehicle-treated cohort does not impede the ability to differentiate antiarthritic efficacy from handling stress.

\section{Objective 3: Recommended Rodent Models of Immune-Mediated Arthritis for Use as Rheumatoid Arthritis Surrogates in Preclinical Drug Development}

The choice of RMIA depends on several factors. The first is the nature of the question being investigated. Basic research may be pursued using any RMIA, but where available a mouse model that has been genetically engineered to overexpress or lack a particular gene often provides the most straightforward means of testing a molecule-specific hypothesis. Examples include the use of IL-1ra knockout mice $[33,80]$ or TNF-transgenic mice $[34,77,151,152]$ to assess the impact of IL-1 (without interference by its endogenous soluble receptor, IL-1ra) or excessive TNF- $\alpha$ on arthritis progression, respectively. The second factor will be the reproducibility of the model. For example, essentially $100 \%$ of animals induced to develop AIA will actually present with acute disease by 9 days after initial inoculation with the arthritogen, and $100 \%$ of rats treated to produced chronic SCW will undergo reactivation of residual disease within 1 to 2 days of reinjecting the arthritogen. Such reliable induction permits treatment groups to be completely filled at one time. In contrast, the incidence of CIA in Lewis rats varies from $60 \%$ to $90 \%$ across laboratories, and arthritis develops over approximately a 5-day period usually starting 11 days after immunization. Accordingly, treatment groups in CIA studies must be enrolled over time, which complicates the treatment matrix of the study. Both genetically engineered and spontaneous RMIA also tend to require sporadic enrollment as the onset of disease may be spread over days to weeks. The third factor will be cost. Genetically engineered and spontaneous disease models may be quite expensive. Spontaneous arthritis in MRL/lpr mice typically does not strike until five or more months of age [87], which will increase the husbandry cost relative to shorter models.

The most suitable RMIA for preclinical development are the induced diseases that have been proven to predict the responsiveness of human RA patients: AIA, CIA, and SCW $[37,153]$ (Table 2). The structural lesions in CIA are 
more analogous to human RA $[38,39]$. However, AIA has been used more extensively for pharmaceutical testing, so more data exist for cross-species comparison of antiarthritic efficacy. In our experience, all three of these models may be reliably elicited in rats, while mice develop CIA but are relatively resistant to classic AIA [48] and SCW [28, 44]. As noted above, mouse CIA exhibits a more variable disease pattern relative to the rat counterpart, and murine joints are very small. Accordingly, we recommend that preclinical efficacy studies of antiarthritic agents in RMIA be undertaken in rats.

Several other practical reasons recommend rat models of arthritis over mouse models if equivalent systems are available in both species (e.g., CIA). One reason for this position is that rats are larger, so certain procedures are more readily accomplished in this species. Ante mortem examples include intra-articular injections and blood sampling (for biomarker analysis), while the most critical postmortem instance is tissue trimming (to consistently orient joints for histologic sectioning). A second reason for preferring rats is that the distribution and extent of inflammatory changes in arthritic joints is more reproducible, typically developing first as a symmetric swelling of both hind paws before progressing to both fore paws $[93,94]$. In contrast, mice inoculated with an arthritogenic agent typically present first with modest swelling of only one fore paw or one hind pawand often only of a single interphalangeal (toe) joint. A third reason for favoring rats is that knowledge regarding the many genes that control induction of immune-mediated arthritis is better understood in this species [27, 28]. Potential disadvantages of using rat arthritis models include the larger specimen size, thereby requiring removal of the phalanges (with loss of their joints to analysis) and more cassettes for histologic processing and the more limited ability for genetic engineering (especially gene targeting (knockout)) in rats versus mice. These drawbacks are minor when compared to the benefits offered by the more reproducible and easily manipulated rat-based RMIAs.

\section{Objective 4: Suitable Procedures for Reproducible Production and Appropriate Assessment of Rat Models of Immune-Mediated Arthritis}

This section briefly summarizes the experimental procedures employed by our laboratory to reproducibly generate and analyze RMIA for an industrial preclinical drug development program. The workhorse models are rat AIA-Myc, rat CIA, and to a much lesser degree rat SCW (Table 2). These RMIA were selected because of their widespread acceptance, and especially because of their utility as surrogates for predicting the response of RA patients to antiarthritic treatments [37, 153]. Novel molecules are tested first in AIA-Myc (as rats develop arthritis in a highly predictable time frame and with a very uniform morphologic pattern) and then in rat CIA (due to its greater degree of similarity to RA). Drug candidates are tested in SCW, and occasionally in mouse CIA, only to provide more data for comparing the relative efficacy of lead candidates slated for human clinical trials (Table 3).
6.1. Induction of Rodent Models of Immune-Mediated Arthritis. All in vivo RMIA should be undertaken in accredited facilities (e.g., by the Association for Assessment and Accreditation of Laboratory Animal Care International (AAALAC)) in accordance with appropriate regulatory guidelines (e.g., "Guide for the Care and Use of Laboratory Animals" (The National Academies Press, Washington, D.C.)). Humane endpoints and veterinary care needs should be clearly outlined in animal care and use protocols and approved by the Institutional Animal Care and Use Committee in advance. In general, analgesics cannot be given because their anti-inflammatory activities tend to inhibit arthritis induction and progression. Instead, additional veterinary support such as fluid therapy, easier access to nutritional sources (e.g., food pellets placed at floor level), and/or supplemental cushioning may be provided during advanced stages of disease. The most humane practice, which is always followed in our laboratory, is to limit the length of RMIA to the shortest possible time required to answer a given experimental question. This period is usually one week after the onset of clinical disease in our AIA, CIA, and SCW models.

Adjuvant-Induced Arthritis. This model is produced in young adult (7- to 8-week-old), male Lewis rats. Animals are inoculated with a single intradermal injection at the tail base of heat-killed Mycobacterium tuberculosis H37Ra (0.5 mg; Difco Laboratories, Detroit, MI) suspended in $0.05 \mathrm{~mL}$ paraffin oil (Crescent Chemical Co., Hauppauge, NY). Animals are acclimated for one week and then randomly assigned to treatment groups ( $n=6$ to 8 ). This group size is used because interindividual variability in the initial disease severity and the day of onset is minimal [4]. Arthritis reliably develops in both hind paws of $100 \%$ of the animals on the 9th day after arthritogen inoculation [4].

The course of rat AIA-Myc can be separated into three stages using a combination of macroscopic and microscopic findings [94]. The "preclinical" phase extends from the day of arthritogen administration until the day of disease onset (which is designated Study Day 0). The "acute clinical" phase, encompassing the peak of active disease, extends from Study Day 0 to Study Day 10 and is characterized by body weight loss, progressive inflammation and skeletal erosion in the hind paws and knees (Figure 2(c)), and the onset of disease in the forepaws (typically at Study Day 7). The "chronic clinical" phase represents all times beyond Study Day 11, at which time lesions have stabilized. Leukocyte and osteoclast numbers begin to regress by approximately four weeks after disease onset [8], presumably because the total loss of articular cartilage and extensive destruction of adjacent bone has removed the inciting antigen.

Collagen-Induced Arthritis. This model is performed in young adult (7- to 8-week-old), female Lewis rats. Animals are immunized by intradermal injection of emulsified porcine type II collagen (Chondrex, Redmond, WA) in IFA at ten different sites $(100 \mu \mathrm{L}$ per site $)$ over the back; other researchers use a lesser number of inoculations (e.g., four [37]), which result in less aggressive joint involvement. The arthritogen is prepared by dissolving collagen $(10 \mathrm{mg})$ in 
TABLE 2: Initiation of major induced rat models of immune-mediated arthritis commonly used in preclinical development.

\begin{tabular}{|c|c|c|c|c|c|c|c|c|}
\hline Model & Inciting agents & Adjuvant & Strain & Gender & Inoculation route & $\begin{array}{c}\text { Day of disease } \\
\text { onset }\end{array}$ & Incidence & $\begin{array}{c}\text { Group } \\
\text { size }\end{array}$ \\
\hline $\begin{array}{l}\text { Adjuvant- } \\
\text { induced } \\
\text { arthritis } \\
\text { (AIA-Myc) }\end{array}$ & $\begin{array}{l}\text { Mycobacterium } \\
\text { tuberculosis H37Ra } \\
\text { (heat-killed) }\end{array}$ & Paraffin oil & Lewis & Male & $\begin{array}{l}\text { Intradermal (once } \\
\text { at the tail base) }\end{array}$ & 9 & $100 \%$ & $\begin{array}{l}6 \text { or } \\
\text { more }\end{array}$ \\
\hline $\begin{array}{l}\text { Collagen- } \\
\text { induced } \\
\text { arthritis (CIA) }\end{array}$ & $\begin{array}{l}\text { Type II collagen } \\
\text { (porcine) }\end{array}$ & $\begin{array}{l}\text { Incomplete } \\
\text { Freund's } \\
\text { adjuvant }\end{array}$ & Lewis & Female & $\begin{array}{l}\text { Intradermal ( } 10 \\
\text { sites over the back) }\end{array}$ & 9 to 11 & $\begin{array}{l}80 \% \text { up } \\
\text { to } 100 \%\end{array}$ & $\begin{array}{l}8 \text { or } \\
\text { more }\end{array}$ \\
\hline $\begin{array}{l}\text { Streptococcal } \\
\text { cell } \\
\text { wall-induced } \\
\text { arthritis } \\
(\mathrm{SCW})\end{array}$ & $\begin{array}{l}\text { Cell wall } \\
\text { peptidoglycan- } \\
\text { polysaccharide } \\
\text { (PG-PS 100P) } \\
\text { from Streptococcus } \\
\text { pyogenes, Group A, } \\
\text { strain D58 }\end{array}$ & $\begin{array}{l}\text { Phosphate- } \\
\text { buffered } \\
\text { saline }\end{array}$ & Lewis & Female & $\begin{array}{l}\text { Intra-articular } \\
\text { (induction); } \\
\text { intravenous } \\
\text { (reactivation) }\end{array}$ & $\begin{array}{c}29 \text { or } 30 \\
\text { (reactivated) }\end{array}$ & $\begin{array}{l}90 \% \text { up } \\
\text { to } 100 \%\end{array}$ & $\begin{array}{l}8 \text { or } \\
\text { more }\end{array}$ \\
\hline
\end{tabular}

TABle 3: Antiarthritic efficacy varies among different rodent models of immune-mediated arthritis.

\begin{tabular}{lcc}
\hline Arthritis model & $\begin{array}{c}\text { Species } \\
\text { (strain) }\end{array}$ & $\begin{array}{c}\text { Maximum } \\
\text { inhibition }\end{array}$ \\
\hline $\begin{array}{l}\text { Adjuvant arthritis, lipoidal } \\
\text { amine (AIA-LA) }\end{array}$ & Rat (Lewis) & $20-30 \%$ \\
$\begin{array}{l}\text { Adjuvant arthritis, } \\
\begin{array}{l}\text { Mycobacterium (AIA-Myc) } \\
\text { Collagen-induced arthritis } \\
\text { (CIA) }\end{array}\end{array}$ & Rat (Lewis) & $30-60 \%$ \\
$\begin{array}{l}\text { Collagen-induced arthritis } \\
\text { (CIA) }\end{array}$ & Rat (DA) & $\sim 25 \%$ \\
$\begin{array}{l}\text { Streptococcal cell wall arthritis } \\
\text { (SCW) }\end{array}$ & Rat (Lewis) & $90-100 \%$ \\
\hline $\begin{array}{l}\text { Collagen-induced arthritis } \\
\text { (CIA) }\end{array}$ & $\begin{array}{c}\text { Mouse } \\
\text { (DBA/1) }\end{array}$ & $90-100 \%$ \\
\hline
\end{tabular}

Treatment regimen: recombinant human interleukin-1 receptor antagonist (IL-1ra), infused at $5 \mathrm{mg} / \mathrm{kg} / \mathrm{hr}$ for 7 days beginning at disease onset by subcutaneous osmotic minipump.

$0.1 \mathrm{~N}$ acetic acid $(5 \mathrm{~mL})$ two days prior to use while stirring on a rotating plate in the refrigerator. The collagen is then emulsified 1: 1 with IFA (Difco Laboratories), yielding a final concentration of $1 \mathrm{mg} / \mathrm{mL}$, using an emulsification needle and glass syringes (Popper and Sons, New Hyde Park, NY). Animals are acclimated for one week and then randomly assigned to treatment groups $(n=8)$. This group size is used because interindividual variability in initial disease severity is minimal [93]. Arthritis develops in at least one hind paw, and usually both, in $80 \%$ to $100 \%$ of the animals between the 9th and the 11th day after injection of the arthritogen.

The course of rat CIA also can be separated into three stages using a combination of macroscopic and microscopic findings [93]. The "preclinical" phase extends from the day of collagen immunization until the day of disease onset in the hind paws (designated Study Day 0). The "acute clinical" phase, which encompasses the peak of active disease, extends from Study Day 0 to Study Day 14 and is characterized by body weight loss, progressive inflammation and skeletal erosion in the hind paws, and the onset of disease in the forepaws (typically at Study Day 7). The "chronic clinical" phase represents all times beyond Study Day 14, at which time lesions have plateaued in both forepaws and hind paws.

Streptococcal Cell Wall-Induced Arthritis. This model is undertaken in young adult (7- to 8-week-old), female Lewis rats using purified peptidoglycan-polysaccharide (PG-PS) cell wall polymers isolated from Streptococcus pyogenes, Group A, D58 strain (PG-PS 100P; Lee Laboratories, Grayson, GA). The arthritogen is prepared by suspending PG-PS $(0.09 \mathrm{~mL}$, containing $600 \mu \mathrm{g}$ of rhamnose) and phosphate-buffered saline (PBS, $0.91 \mathrm{~mL}$ ) by sonication for 10 minutes, after which it is used immediately. Rats are anesthetized deeply to permit direct intra-articular injection of the PG-PS suspension ( $10 \mu \mathrm{L}$, containing $6 \mu \mathrm{g}$ of rhamnose) into one tibiotarsal (ankle) joint per animal using a 30-gauge needle; the intra-articular injection is repeated if the diameter of the induced hind paw does not equal or exceed $7.0 \mathrm{~mm}$ after 24 hours. Animals are maintained for 4 weeks (to allow acute inflammation to subside into chronic disease), after which they are randomized by ankle diameter into treatment groups $(n=8)$. Arthritis is reactivated on day 29 or 30 after the initial intra-articular induction by intravenous injection of PG-PS/PBS suspension $(35 \mu \mathrm{L}$, containing about $200 \mu \mathrm{g}$ of rhamnose). Arthritis develops in the injected hind paw in $90 \%$ to $100 \%$ of the animals between the 1 st and the 2 nd days after disease reactivation. Paw swelling peaks at 72 hours after reactivation and then regresses rapidly over the next several days. Alternatively, SCW polyarthritis may be induced by parenteral administration (e.g., intraperitoneal) of PGPS, with the nature of the lesions depending on how long clinical and histopathologic analyses are delayed after PG-PS administration [154]. To our knowledge, no detailed study has been published defining the progression of either acute or chronic SCW in rats. 
6.2. Assessment of Arthritis. Analytical tests applied to RMIA can be separated in three fashions. The first is by tiers, where Tier 1 includes routine screening procedures while Tier 2 represents specialized methods that are undertaken only as needed to answer distinct questions. The second classification scheme is to divide the tests by the time frame during which they are performed (i.e., antemortem versus postmortem). The final categorization is by invasiveness of the test. Measurements of total body weight and paw swelling may be taken repeatedly over time without inflicting any wound, and blood sampling to measure serum biomarkers is minimally invasive as long as blood collection is not excessive (no more than $0.5 \%$ of body weight, or about $1 \mathrm{~mL}$ of blood from a $250 \mathrm{~g}$ rat). In contrast, histopathologic analysis requires that affected joints be removed and processed prior to evaluation.

Routine Screening Tests (Tier 1). These methods are used on all RMIA in our laboratory and include total body weights, measurement of hind paw swelling, calculation of bone mineral density (BMD) loss, and histopathology. Total body weight and paw swelling are evaluated daily from the day of disease onset throughout the treatment period (and any recovery period) to provide a graphic representation of disease progression. Paw swelling is assessed by one of two techniques: plethysmography [4], which calculates the degree of paw volume expansion by computing the weight of fluid displaced by the swollen limb upon immersion in a water-filled beaker balanced on a commercial scale, or caliper measurements to define the diameter of the affected joint(s). Plethysmography is best suited for massively swollen AIA hind paws and calipers for more modestly swollen hind paws in CIA and SCW, but either technique may be applied successfully to any of these rat models.

After necropsy, the hind paws are removed at the fur line (just proximal to the hock (ankle)). One paw is stored in $70 \%$ ethanol at room temperature until dual X-ray absorptiometry (DXA) can be used to assess BMD loss [4]. The degree of BMD reduction is dictated by the extent of leukocyte infiltration as osteoclast recruitment along bony surfaces is induced by numerous proinflammatory cytokines [155]; accordingly, bone dissolution is more severe in AIA (Figure 4), where leukocyte influx is more severe than in CIA or SCW. The other paw is fixed by immersion in either $70 \%$ ethanol (to serve as a potential backup sample for DXA or a substrate for molecular pathology studies) or either neutral buffered $10 \%$ formalin or zinc formalin (to provide the best morphologic preservation of infiltrating leukocytes) at room temperature for 72 to 96 hours. Fixed specimens are decalcified in eight serial changes of a 1:4 mixture of $8 \mathrm{~N}$ formic acid and $1 \mathrm{~N}$ sodium formate for approximately a week; more rapid decalcification may be achieved by using a 1:1 mixture, but delicate tissue antigens may be too degraded for subsequent molecular pathology analysis. The digits (toes) are then removed from the demineralized hind paws by cutting across the metatarsals (the "arch" of the "foot") midway between the tip of the toes and the hock, after which the paw is divided longitudinally into approximately equal halves by cutting just lateral to the tibia and between the 2nd and the 3rd digits (Figure 5). The two halves are placed into a single cassette and processed into paraffin using routine procedures. Embedded specimens are faced to expose the distal tibia and entire talus, after which several serial 4 - to $8-\mu \mathrm{m}$-thick sections are cut.

Routine histopathologic analysis for Tier 1 is performed using one to three slides. The first slide is stained with hematoxylin and eosin (H\&E) for evaluation of general structural characteristics such as leukocyte infiltration, skeletal erosion, periosteal proliferation, and (in CIA only) pannus production (Figure 6). The second slide may be processed by indirect immunohistochemistry or in situ hybridization to detect the osteoclast marker cathepsin $\mathrm{K}$ [102]. If desired, cathepsin $\mathrm{K}$ immunohistochemistry may be followed by an H\&E counterstain to avoid the need for the H\&E-stained slide; this procedure may be automated for higher throughput. The third slide is stained with either safranin $\mathrm{O}$ or toluidine blue (Figure 6) to evaluate the degree of matrix integrity in articular cartilage. As the extent of inflammation increases, the articular cartilage loses matrix proteins and can no longer bind dye $[8,156]$. In practice, the loss of cartilage matrix is so advanced in chronic arthritis that this latter stain may be omitted if the disease has been present for more than five (for AIA) to ten (for CIA) days. Histopathologic data for Tier 1 screening is performed using semiquantitative grading scales (normal joint, or minimal, mild, moderate, or marked disease), which can be rapidly gathered by an experienced pathologist (10 to 60 seconds per section for all stains, depending on the complexity of the lesion).

Specialized Tests (Tier 2). The procedures used in our laboratory are applied in addition to, not instead of, the Tier 1 methods. For example, a detailed examination of local and systemic events in RMIA requires evaluation of numerous parameters other than involvement of joints in the distal limbs. Whole blood may be collected for hematologic counts, or to harvest serum to measure circulating levels of biomarkers and immune proteins $[93,94]$. For comparison, unfixed joints may be homogenized to extract and quantify local biomarkers [93, 94]. Extra-articular tissues (especially hematopoietic organs like bone marrow, lymph nodes, or spleen) may be isolated to correlate tissue leukocyte numbers to circulating cell counts by flow cytometry or histopathology $[93,94]$ or to permit evaluation of systemic bone loss at sites distant from affected joints (e.g., lumbar vertebrae [10]). Diseased joints may be imaged using conventional radiography [105], computed tomography [26, 157, 158], or magnetic resonance imaging [157]. Paws may be harvested and split longitudinally while fresh using a circular, watercooled diamond saw (e.g., Isomet Low Speed model; Buehler, Lake Bluff, IL) to provide for more rapid penetration of fixative; subsequent fixation time can be reduced substantially, thereby reducing the degradation of delicate antigens and nucleic acids while retaining good tissue morphology.

The routine Tier 1 semiquantitative histopathologic analysis may be augmented in Tier 2 by supplementary endpoints. One common approach is to include additional special stains to demonstrate other constituents in the 


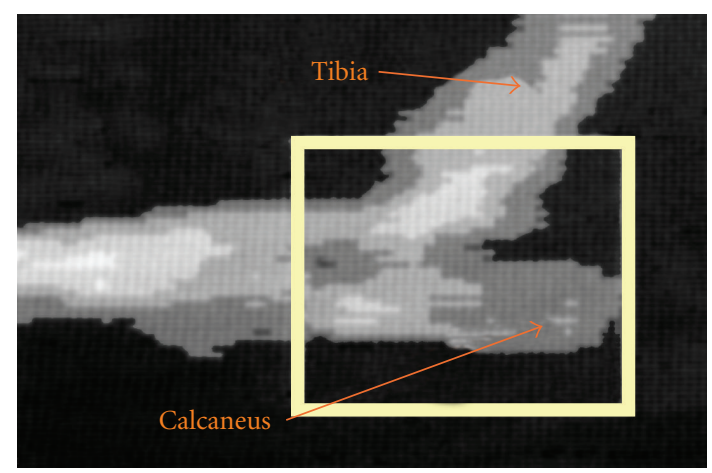

(a)

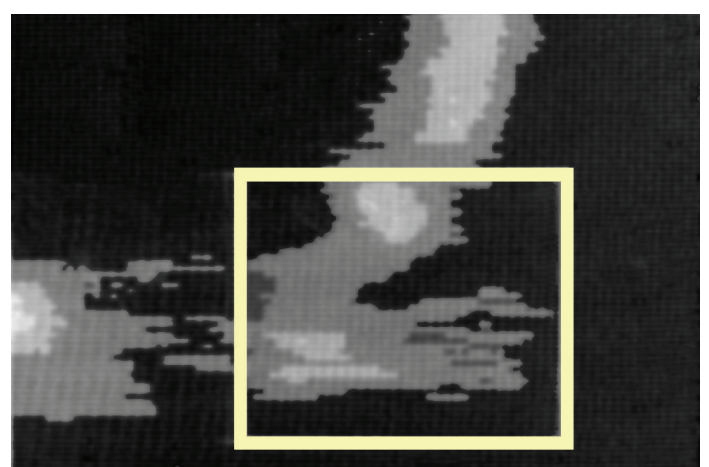

(b)

FIGURE 4: Bone mineral density (BMD) of the tibiotarsal region (hock (or "ankle")) by dual X-ray absorptiometry (DXA) is a rapid means of evaluating bone integrity in arthritic rodent hind paws. Relative to a nonarthritic control (a), BMD is greatly reduced in multiple bones (bordered by the yellow rectangle) of a young adult, male Lewis rat with the mycobacterial variant of adjuvant-induced arthritis (AIA-Myc). These panels are reproduced from [155] with the permission of the American College of Rheumatology.

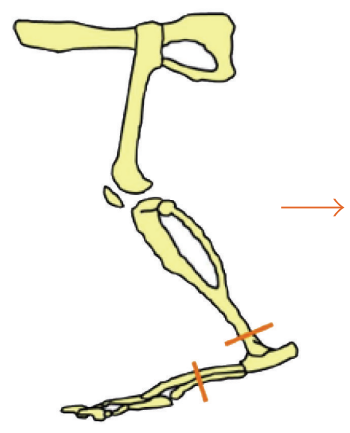

(a)

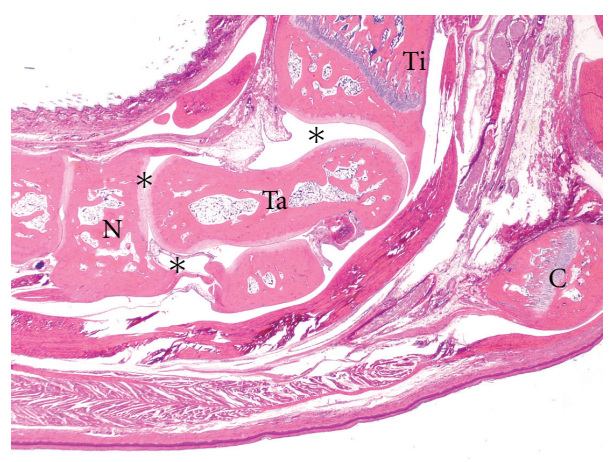

(c)
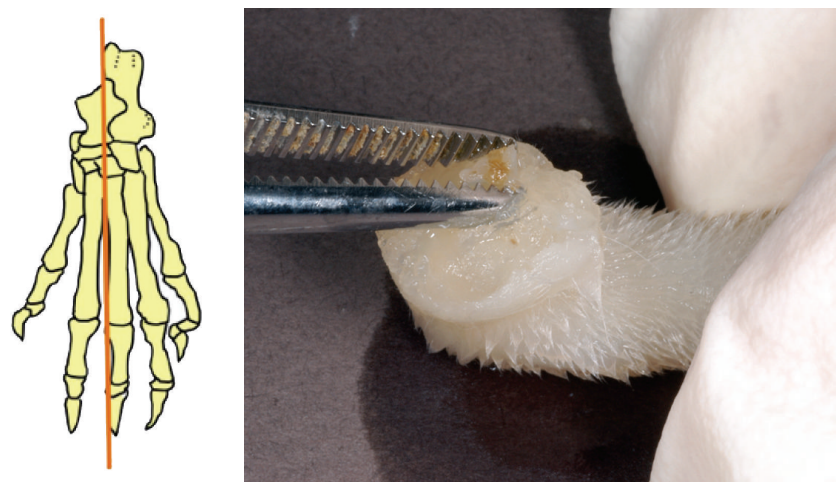

(b)

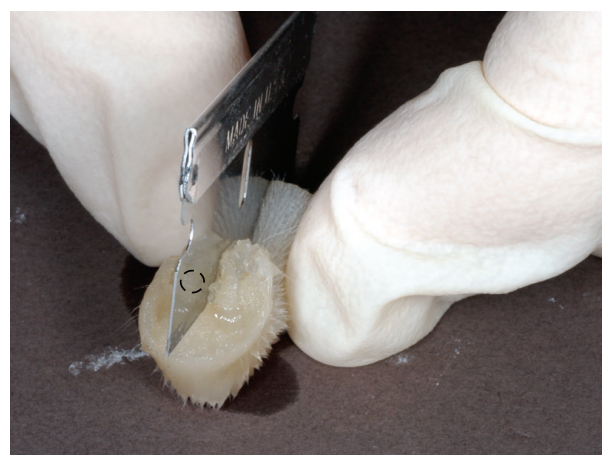

(d)

Figure 5: Tissue trimming procedure for reliable and reproducible production of high-quality hind paw sections for histopathological analysis of immune-mediated arthritis in rodents. A skeletal schematic diagram (a) shows the location of the cuts required to isolate the tibiotarsal region. As viewed from the lateral side (a (left panel)), the hind paw is separated from the distal limb just above the tibiotarsal (hock (or "ankle")) region at the fur line, and the digits (toes) are removed. From the top (a (right panel)), the hind paw is divided longitudinally using a cut placed between metatarsals II and III, which will fall just to the outside of the talus (the uppermost bone to the left of the orange line) and tibia (the distal leg bone (not shown)) that articulates with the talus. The distal tibia ((b), bracketed by forceps) is identified at the proximal cut margin of isolated hind paws as an oval white bone with a yellow/brown core of bone marrow. The longitudinal dividing cut (d) is made from the dorsal side by engaging the blade at the proximal and distal margins of the sample and then cutting straight down; the dashed black oval indicates the position of the tibia behind the razor blade, indicating that the blade is located just to the side of this bone. The microscopic structure of hind paw sections taken through this region from a nonarthritic rat (c) will include the joint spaces most susceptible to induced models of immune-mediated arthritis (asterisks $\left({ }^{*}\right)$ ) as well as the most affected tarsal bones (navicular $(\mathrm{N})$ and talus $(\mathrm{Ta})$ ), the distal tibia (Ti), and sometimes the calcaneus (C (or "heel")). Histologic stain: hematoxylin and eosin (H\&E). 


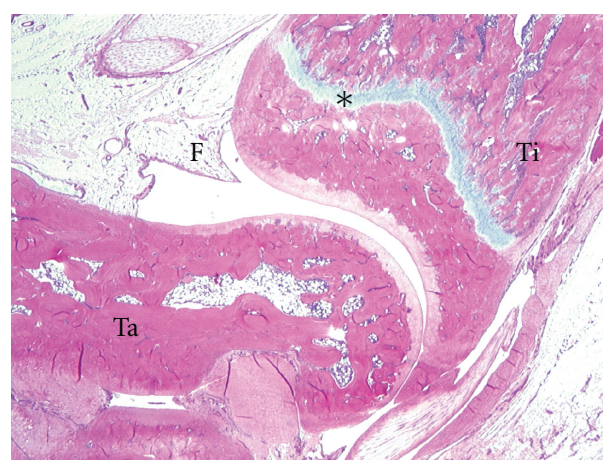

(a)

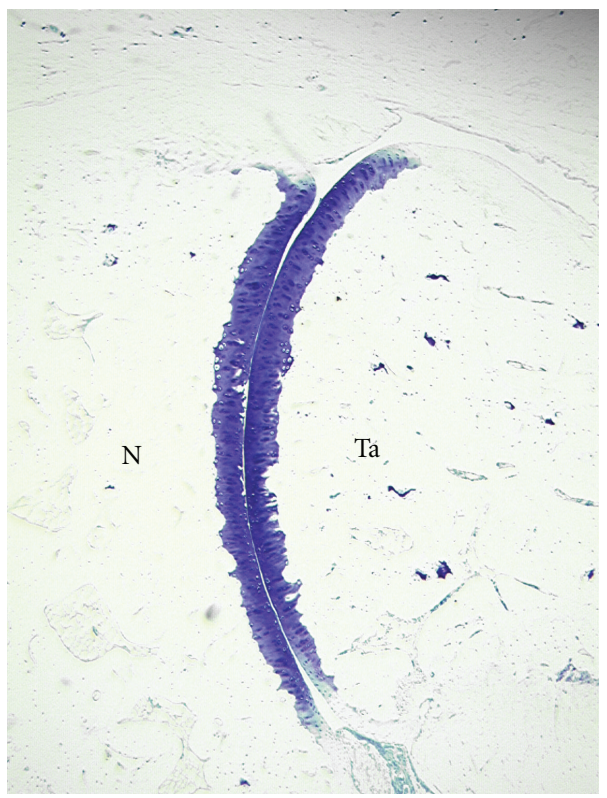

(c)

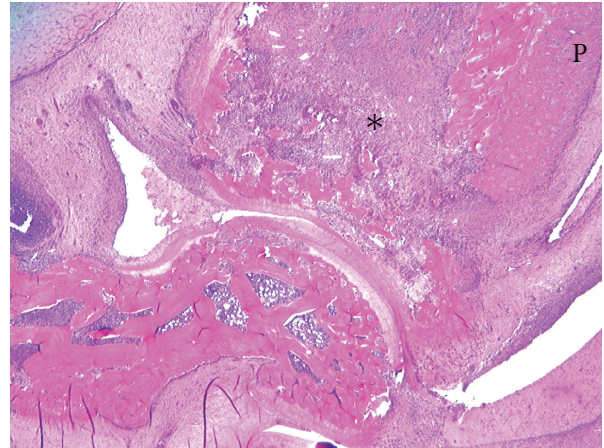

(b)

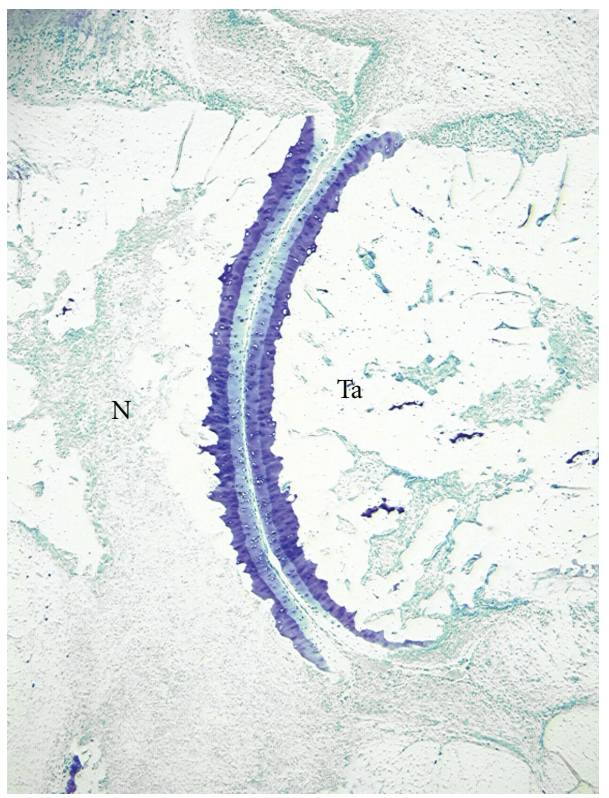

(d)

FIGURE 6: Structural lesions of immune-mediated joint disease in arthritic rodents include both skeletal and soft tissue changes. Relative to nonarthritic control animals ( (a) and (c)), young adult, male Lewis rats with the aggressive mycobacterial variant of adjuvant-induced arthritis (AIA-Myc) ((b) and (c)) develop extensive inflammation of the fatty periarticular soft tissues (F) and bone marrow, erosion of cortical and trabecular bone, loss of physeal (growth plate) cartilage (asterisks $(*)$ ), and exuberant production of periosteal bone $(\mathrm{P})$. Fibrin, inflammatory cells, and (for CIA) pannus are additional features that may be evident on hematoxylin and eosin (H\&E)-stained sections ((a) and (b)). Cartilage degeneration is demonstrated by toluidine blue staining ((c) and (d)), with the normal uniform dark purple labeling of surface and deep articular cartilage in nonarthritic controls (c) being replaced in inflamed joints by loss of staining in the superficial matrix of arthritic rats (d). Extensive loss of subchondral and trabecular bone (pale white plates and columns adjacent to cartilage) results from extensive infiltration of the bone marrow by inflammatory cells (punctate gray/green fields between bones in $(\mathrm{d})$ ). Abbreviations: $\mathrm{N}=$ navicular tarsal bone, $\mathrm{Ta}=$ talus, $\mathrm{Ti}=$ tibia .

arthritic process, such as markers for blood vessels [101], different populations of leukocytes, or expression of various proinflammatory and proerosive mediators [10]. Another option is to examine lesions in other joints besides those of the affected paws. In this regard, preferred choices are the knee (Figure 7) and the interphalangeal (toe) joints. Considerable care must be taken to ensure that the specimen is positioned correctly during trimming so that sections are oriented in the optimal plane; for example, a frontal view is preferred for the knee to allow maximal scrutiny of the articular surface [62]. A final variant is to procure quantitative data from histopathologic sections [101, 102].
Such special analyses require at least some extra time, and often a great deal of it, so should not be undertaken lightly in the course of preclinical development programs.

\section{Objective 5: Considerations in Model Selection and Experimental Design}

The current section will briefly examine several practical principles that must be contemplated when using the induced RMIA that we recommend above. Failure to consider such points may delay the launch of studies, result in their premature termination, or require their repetition. 


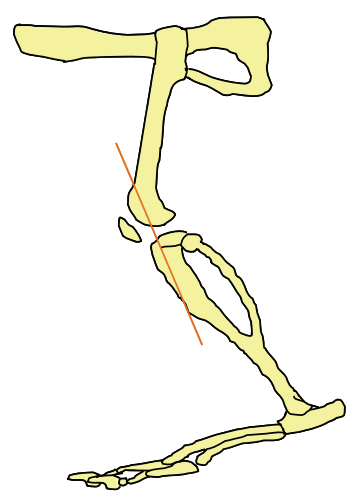

(a)

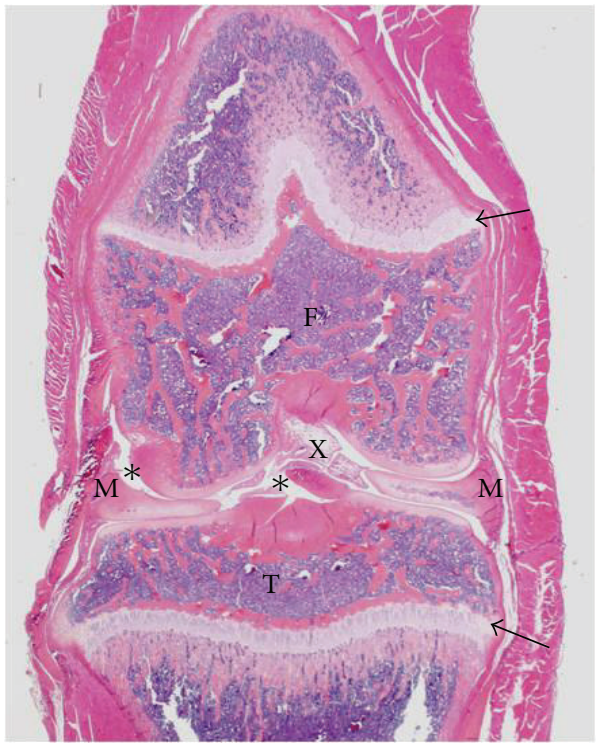

(c)

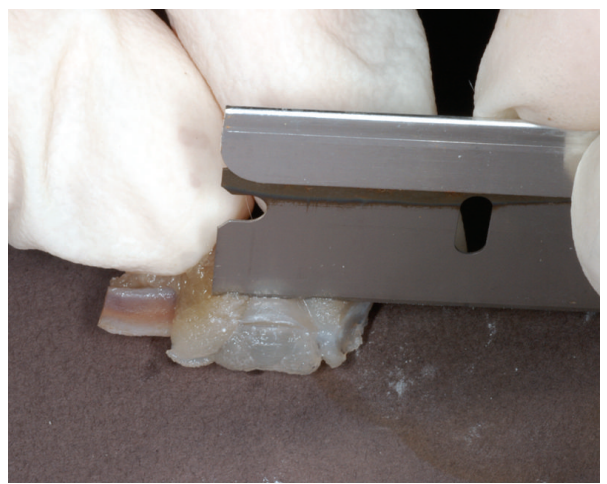

(b)

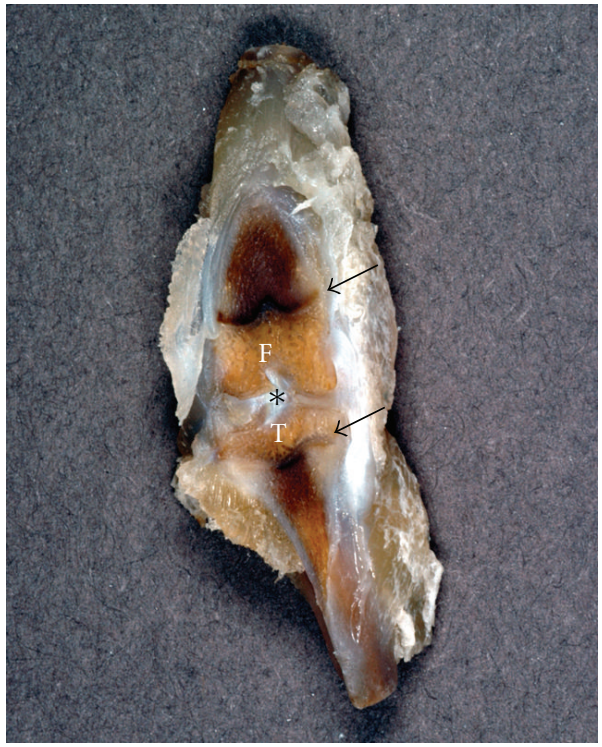

(d)

FIGURE 7: Tissue trimming procedure for reliable and reproducible production of high-quality sections through the rodent femorotibial (knee) joint. A skeletal schematic diagram (a) shows the location of the cut required to isolate the knee region at the appropriate plane, as viewed from the lateral side. The tissue along the cranial (front) surface of the knee is removed ((b), oriented with the distal tibia to the left) a few millimeters at a time while holding the razor blade parallel with the cranial surface of the tibia. The appearance of the properly trimmed joint (d) will show the distal femur (F) and proximal tibia (T) separated by the joint space (asterisk $\left({ }^{*}\right)$ ), as well as the physis (growth plate) for both bones (arrows). The appearance of the corresponding histologic section from a nonarthritic rat (c) reveals additional features within the joint space including the menisci $(\mathrm{M})$ associated with the femoral condyles and the cruciate ligaments (X). Histologic stain: hematoxylin and eosin (H\&E).

Time spent in optimizing RMIA up front will save significant effort, money, and time when building a research program and generating the preclinical portion of a product registration package.

7.1. Genetic Background. In general, routine rodent arthritis studies should be performed in strains that are inherently sensitive to induction of immune-mediated joint disease. In our experience, the preferred wild-type strains are Lewis rats, which exhibit an intermediate susceptibility to disease (Figure 1), and DBA/1 mice. Each laboratory will have to validate that the animals from their supplier are sufficiently vulnerable to arthritis induction and will have to ensure that genetic drift does not alter the substrain's sensitivity over time [29].
7.2. Choice of Inducing Agent. The type of adjuvant influences the course of RMIA. As shown in Figure 2, rats with AIA-LA and AIA-Myc have different patterns of lesions and divergent dose responses to antiarthritic molecules. Similarly, induction of CIA in mice using the weak adjuvant IFA results in reduced susceptibility to arthritis relative to animals in which the carrier was complete Freund's adjuvant (CFA) [159]. The source of adjuvant may impact the extent of disease as well (Figures 1 and 3 ).

7.3. Microbial Flora. The bacterial composition may play a large role in defining the sensitivity of various rodent strains to arthritogenic stimuli. For example, arthritis-resistant F344 rats become vulnerable to AIA when housed under germfree conditions [160]. In contrast, the germfree state prevents 
development of inflammatory diseases in joints (and the intestinal tract) of HLA-B27-transgenic rats $[81,82]$. In our experience, preclinical development programs are best performed in rodent strains (such as Lewis rats), where an intermediate susceptibility to arthritis is compatible with the presence of a normal microbial complement, thereby avoiding the need for expensive germfree husbandry practices.

7.4. Treatment Regimen. The responsiveness of RMIA to antiarthritic agents is variable. Importantly, the pharmacological target must be a major player in the RMIA selected. In general, aggressive RMIA are unresponsive to weak antiinflammatory agents like nonsteroidal anti-inflammatory agents (NSAIDs) - although AIA is easily inhibited with cyclooxygenase inhibitors-but are sensitive to more potent molecules (e.g., anticytokine biologics, corticosteroids, and disease-modifying antirheumatic drugs (DMARDS)). Less destructive RMIA like CIA and SCW are more responsive to all classes of agents. In fact, each RMIA embodies one distinct disease in one individual (inbred strain) as contrasted to human RA, which represents a continuum of disease expressions in an outbred population. Thus, the heterogeneity of pharmacological responses in RMIA reflects the heterogeneity of therapeutic success in RA.

The impact of antiarthritic agents on immune-mediated arthritis is dependent on several factors. The most obvious is dose. Higher doses of antiarthritic molecules usually produce greater reductions in arthritis parameters than do lower doses [4]. That said, the shape of the dose-response curve will not always be linear (Figure 2) [8]. A second factor is the time at which an antiarthritic agent is administered. The production of proinflammatory mediators waxes and wanes $[93,94,161]$, so achieving a therapeutic effect is dependent on when therapeutic molecules are administeredparticularly when cytokines and chemokines are targeted with specific inhibitors. For example, cyclosporin A is an effective immunosuppressant that can significantly inhibit hind paw swelling in rat CIA (Figure 8). However, shifting the time frame over which cyclosporin $\mathrm{A}$ is delivered can even potentiate disease [162], resulting in an earlier onset or increased severity, or delay disease onset (Figure 8). A final factor is the nature of the target for an antiarthritic agent. For example, osteoprotegerin (OPG) is a soluble receptor for the proerosive ligand RANKL. Administration of OPG to rats with AIA-Myc essentially halts bone erosions even in the face of severe joint inflammation but has very little impact on the inflammatory component of disease $[8,99,156]$. In contrast, IL-1ra and sTNFR-1 are inhibitors of IL-1 and TNF$\alpha$, respectively. Administration of these latter two agents blocks inflammation, and as a secondary consequence it prevents skeletal damage as well [4]. Thus, the nature of anticipated therapeutic benefit may dictate the design of the experiment and/or analysis.

\section{Summary}

Various rodent models of arthritis are the conventional means of evaluating hypothetical mechanisms of immune-

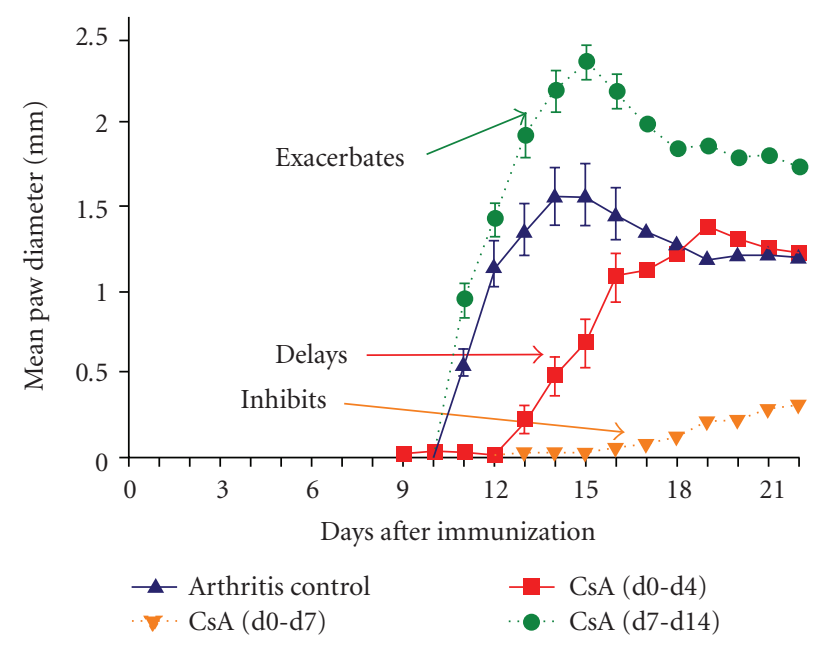

FIgURE 8: The effect of cyclosporin A (CsA), a potent immunosuppressant, on the extent of collagen-induced arthritis (CIA) in young adult, female Lewis rats depends on the treatment schedule. The course of CIA in untreated animals (arthritis control) is represented by the solid blue line with triangular data points. Administration of CsA on the day of arthritis induction (designated as $\mathrm{d} 0$ ) for 7 consecutive days ( $\mathrm{d} 0$ to $\mathrm{d} 7$ ) substantially inhibits hind paw swelling (orange-dotted line with inverted triangles). Early but abbreviated treatment with CsA (d0 to $\mathrm{d} 4$ ) delays disease onset but does not impact its ultimate severity (solid red line with squares). Delayed exposure to CsA ( $\mathrm{d} 7$ to $\mathrm{d} 14$ ) greatly exacerbated the degree of hind paw swelling (green-dotted line with circles). Bars associated with data points represent standard error of the mean. Treatment regimen: CsA was given at $25 \mathrm{mg} / \mathrm{kg} /$ day by gavage.

mediated joint disease and the comparative efficacy of novel drug candidates with potential antiarthritic efficacy during preclinical development. The workhorse models are polyarthritides in rats and mice induced by injecting either bacterial (especially mycobacterial (AIA-Myc) or streptococcal (SCW)) fragments or collagen type II (usually from a nonrodent mammalian source (CIA)) in adjuvant. Efficacy is typically evaluated by a combination of semiquantitative and quantitative techniques including clinical measurements (e.g., paw volume and serum biomarker concentrations), noninvasive imaging (e.g., bone density analysis and computed tomography), and histopathology scores (e.g., lesion scores for inflammation, joint erosion, osteophyte production, and cartilage degradation).

The extent and severity of arthritis depends on both the experimental methodology (e.g., inciting agent, adjuvant, number, and placement of sensitizing injections) and individual physiologic parameters (e.g., age, gender, and genetics). Similarly, the effectiveness of antiarthritic molecules varies with the nature of the agent, the therapeutic regimen (e.g., dose, route, and schedule of treatment), and the choice of rodent arthritis model. In our experience, rat models of AIA, CIA, and SCW are preferred platforms for preclinical drug development because these rat systems are more reproducible among individuals and across studies than are corresponding mouse models. Of 
these three rat models, AIA is more severe but exhibits the most consistent lesions among study mates and across studies, while CIA delivers joint lesions in rodents with a histopathologic appearance that better resembles that of the human rheumatoid arthritis joint. All the rat models are driven by relative overactivity of proinflammatory and proerosive signaling cascades, but the dominant cytokines differ among the models. As with human clinical experience, the efficacy of various antiarthritic molecules differs among rodent arthritis models, especially when the agent is a specific cytokine inhibitor.

\section{Abbreviations}

AbIA: Antibody-induced arthritis

AIA: Adjuvant-induced arthritis

AIA-LA: Adjuvant-induced arthritis induced with lipoidal amine

AIA-Myc: Adjuvant-induced arthritis induced with heat-killed Mycobacterium sp.

AntIA: Antigen-induced arthritis

BMD: Bone mineral density

CCL2: Chemokine (C-C motif) ligand 2

CIA: Collagen-induced arthritis

CFA: Complete Freund's adjuvant

CsA: Cyclosporin A

CXCL1: Chemokine (C-X-C motif) ligand 1

CXCL8: Chemokine (C-X-C motif) ligand 8

DMARD: Disease-modifying antirheumatic drug

DXA: Dual X-ray absorptiometry

H\&E: Hematoxylin and eosin

HPA: Hypothalamic-pituitary-adrenal

HPG: Hypothalamic-pituitary-gonadal

IFA: Incomplete Freund's adjuvant

IL-1: Interleukin-1

IL-1ra: Interleukin-1 receptor antagonist

IL-4: Interleukin-4

IL-6: Interleukin-6

IL-10: Interleukin-10

IL-17A: Interleukin-17A

MHC: Major histocompatability complex

MMP: Matrix metalloproteinase

NSAID: Nonsteroidal anti-inflammatory agent

PBS: $\quad$ Phosphate-buffered saline

$\mathrm{PGE}_{2}$ : $\quad$ Prostaglandin $\mathrm{E}_{2}$

RA: $\quad$ Rheumatoid arthritis

RANKL: Receptor activator of $\mathrm{NF} \kappa \mathrm{B}$ ligand

RMIA: Rodent model(s) of immune-mediated arthritis

SCID: $\quad$ Severe combined immunodeficiency

SCW: $\quad$ Streptococcal cell wall-induced arthritis

sTNFR: Soluble tumor necrosis factor receptor

TGF- $\beta$ : Transforming growth factor-beta

TNF- $\alpha$ : Tumor necrosis factor-alpha.

\section{Acknowledgments}

The authors thank Dr. Paulette Andrew for technical assistance, Dr. Ruth Lightfoot-Dunn for helpful comments, Mr.
David Glenn (David Glenn Design, Durham, NC) for aid in formatting the graphic figures, and Amgen Inc. (Thousand Oaks, CA) for providing an AAALAC-accredited animal facility and financial support.

\section{References}

[1] H. G. Birnbaum, M. Barton, P. E. Greenberg et al., "Direct and indirect costs of rheumatoid arthritis to an employer," Journal of Occupational and Environmental Medicine, vol. 42, no. 6, pp. 588-596, 2000.

[2] C. K. Kwoh, L. G. Anderson, J. M. Greene et al., "Guidelines for the Management of rheumatoid arthritis: 2002 update-American College of Rheumatology subcommittee on rheumatoid arthritis guidelines," Arthritis and Rheumatism, vol. 46, no. 2, pp. 328-346, 2002.

[3] S. Bläss, J. M. Engel, and G. R. Burmester, "The immunologic homunculus in rheumatoid arthritis. A new viewpoint of immunopathogenesis in rheumatoid arthritis and therapeutic consequences," Zeitschrift für Rheumatologie, vol. 60, no. 1, pp. 1-16, 2001 (German).

[4] U. Feige, Y. L. Hu, J. Gasser, G. Campagnuolo, L. Munyakazi, and B. Bolon, "Anti-interleukin-1 and anti-tumor necrosis factor- $\alpha$ synergistically inhibit adjuvant arthritis in Lewis rats," Cellular and Molecular Life Sciences, vol. 57, no. 10, pp. 1457-1470, 2000.

[5] W. B. van den Berg, "Uncoupling of inflammatory and destructive mechanisms in arthritis," Seminars in Arthritis and Rheumatism, vol. 30, no. 5, pp. 7-16, 2001.

[6] I. Rioja, K. A. Bush, J. B. Buckton, M. C. Dickson, and P. F. Life, "Joint cytokine quantification in two rodent arthritis models: kinetics of expression, correlation of mRNA and protein levels and response to prednisolone treatment," Clinical and Experimental Immunology, vol. 137, no. 1, pp. 65-73, 2004.

[7] M. D. Köller, "Targeted therapy in rheumatoid arthritis," Wiener Medizinische Wochenschrift, vol. 156, no. 1-2, pp. 5360, 2006.

[8] G. Campagnuolo, B. Bolon, and U. Feige, "Kinetics of bone protection by recombinant osteoprotegerin therapy in Lewis rats with adjuvant arthritis," Arthritis and Rheumatism, vol. 46, no. 7, pp. 1926-1936, 2002.

[9] E. M. Gravallese, "Bone destruction in arthritis," Annals of the Rheumatic Diseases, vol. 61, no. 2, supplement, pp. ii84-ii86, 2002.

[10] M. Stolina, S. Adamu, M. Ominsky et al., "RANKL is a marker and mediator of local and systemic bone loss in two rat models of inflammatory arthritis," Journal of Bone and Mineral Research, vol. 20, no. 10, pp. 1756-1765, 2005.

[11] J. Holoshitz, A. Matitiau, and I. R. Cohen, "Arthritis induced in rats by cloned $\mathrm{T}$ lymphocytes responsive to mycobacteria but not to collagen type II," Journal of Clinical Investigation, vol. 73, no. 1, pp. 211-215, 1984.

[12] S. A. Stimpson, R. R. Brown, S. K. Anderle et al., "Arthropathic properties of cell wall polymers from normal flora bacteria," Infection and Immunity, vol. 51, no. 1, pp. 240-249, 1986.

[13] M. P. Hazenberg, I. S. Klasen, J. Kool, J. G. H. Ruselervan Embden, and A. J. Severijnen, "Are intestinal bacteria involved in the etiology of rheumatoid arthritis?" Acta Pathologica, Microbiologica et Immunologica Scandinavica, vol. 100, no. 1, pp. 1-9, 1992. 
[14] K. M. Kulmatycki and F. Jamali, "Drug disease interactions: role of inflammatory mediators in disease and variability in drug response," Journal of Pharmacy and Pharmaceutical Sciences, vol. 8, no. 3, pp. 602-625, 2005.

[15] J. H. Klippel, L. J. Crofford, J. H. Stone, and C. M. Weyand, Primer on the Rheumatic Diseaes, Arthritis Foundation, Atlanta, Ga, USA, 12th edition, 2001.

[16] M. Hegen, J. C. Keith, M. Collins, and C. L. NickersonNutter, "Utility of animal models for identification of potential therapeutics for rheumatoid arthritis," Annals of the Rheumatic Diseases, vol. 67, no. 11, pp. 1505-1515, 2008.

[17] L. Bevaart, M. J. Vervoordeldonk, and P. P. Tak, "Evaluation of therapeutic targets in animal models of arthritis: how does it relate to rheumatoid arthritis?" Arthritis and Rheumatism, vol. 62 , no. 8, pp. 2192-2205, 2010.

[18] C. Bianchi, "Antibody-induced foot oedema, hyperalgesia and monoarticular arthritis in rats, guinea-pigs and rabbits for testing anti-inflammatory, antiarthritic agents," Agents and Actions, vol. 11, no. 6-7, pp. 750-761, 1981.

[19] B. Henderson and E. R. Pettipher, "Comparison of the in vivo inflammatory activities after intra-articular injection of natural and recombinant IL- $1 \alpha$ and IL- $1 \beta$ in the rabbit," Biochemical Pharmacology, vol. 37, no. 21, pp. 4171-4176, 1988.

[20] U. Feige, A. Karbowski, C. Rordorf-Adam, and A. Pataki, "Arthritis induced by continuous infusion of hr-interleukin$1 \alpha$ into the rabbit knee-joint," International Journal of Tissue Reactions, vol. 11, no. 5, pp. 225-238, 1989.

[21] B. A. 'T. Hart, R. A. Bank, J. A. D. M. De Roos et al., "Collagen-induced arthritis in rhesus monkeys: evaluation of markers for inflammation and joint degradation," British Journal of Rheumatology, vol. 37, no. 3, pp. 314-323, 1998.

[22] M. P. M. Vierboom, M. Jonker, R. E. Bontrop, and B. 'T. Hart, "Modelling human arthritic diseases in nonhuman primates," Arthritis Research and Therapy, vol. 7, no. 4, pp. 145-154, 2005.

[23] G. A. Limb, K. A. Brown, R. A. Wolstencroft, B. A. Ellis, and D. C. Dumonde, "The production of arthritis in the guineapig by intra-articular reaction between lymphokines and inflammatory leucocytes," British Journal of Experimental Pathology, vol. 70, no. 4, pp. 443-456, 1989.

[24] N. Yamashita, I. Nakanishi, and Y. Okada, "Arthritis induced immunologically with cationic amidated bovine serum albumin in the guinea pig. A morphological and biochemical study on the destruction of articular cartilage," Virchows Archive B, vol. 60, no. 1, pp. 57-66, 1991.

[25] A. F. Al-Mobireek, A. M. G. Darwazeh, and M. B. Hassanin, "Experimental induction of rheumatoid arthritis in temporomandibular joint of the guinea pig: a clinical and radiographic study," Dentomaxillofacial Radiology, vol. 29, no. 5, pp. 286-290, 2000.

[26] H. Vermeirsch, R. Biermans, P. L. Salmon, and T. F. Meert, "Evaluation of pain behavior and bone destruction in two arthritic models in guinea pig and rat," Pharmacology Biochemistry and Behavior, vol. 87, no. 3, pp. 349-359, 2007.

[27] B. Joe, M. M. Griffiths, E. F. Remmers, and R. L. Wilder, "Animal models of rheumatoid arthritis and related inflammation," Current Rheumatology Reports, vol. 1, no. 2, pp. 139-148, 1999.

[28] R. L. Wilder, E. F. Remmers, Y. Kawahito, P. S. Gulko, G. W. Cannon, and M. M. Griffiths, "Genetic factors regulating experimental arthritis in mice and rats," in Genes and Genetics of Autoimmunity, A. N. Theofilopoulos, Ed., pp. 121-165, Karger, Basel, Switzerland, 1999.
[29] C. Rintisch and R. Holmdahl, "DA rats from two colonies differ genetically and in their arthritis susceptibility," Mammalian Genome, vol. 19, no. 6, pp. 420-428, 2008.

[30] J. G. Fox, S. W. Barthold, M. T. Davisson, C. E. Newcomer, F. W. Quimby, and A. L. Smith, The Mouse in Biomedical Research, Vol 4: Immunology, Academic Press, San Diego, Calif, USA, 2nd edition, 2007.

[31] H. Ibelgaufts, "COPE (Cytokines \& Cells Online Pathfinder Encyclopedia), ed. 24.7," August 2010, http://www.copewithcytokines.de.

[32] H. T. Yang, J. Jirholt, L. Svensson et al., "Identification of genes controlling collagen-induced arthritis in mice: striking homology with susceptibility loci previously identified in the rat," Journal of Immunology, vol. 163, no. 5, pp. 2916-2921, 1999.

[33] R. Horai, S. Saijo, H. Tanioka et al., "Development of chronic inflammatory arthropathy resembling rheumatoid arthritis in interleukin I receptor antagonist-deficient mice," Journal of Experimental Medicine, vol. 191, no. 2, pp. 313-320, 2000.

[34] P. Li and E. M. Schwarz, "The TNF- $\alpha$ transgenic mouse model of inflammatory arthritis," Springer Seminars in Immunopathology, vol. 25, no. 1, pp. 19-33, 2003.

[35] J. W. Gregersen, S. Holmes, and L. Fugger, "Humanized animal models for autoimmune diseases," Tissue Antigens, vol. 63, no. 5, pp. 383-394, 2004.

[36] L. Mandik-Nayak and P. M. Allen, "Initiation of an autoimmune response: insights from a transgenic model of rheumatoid arthritis," Immunologic Research, vol. 32, no. 1-3, pp. 513, 2005.

[37] A. Bendele, J. McComb, T. Gould et al., "Animal models of arthritis: relevance to human disease," Toxicologic Pathology, vol. 27, no. 1, pp. 134-142, 1999.

[38] K. Terato, R. Hashida, K. Miyamoto et al., "Histological, immunological and biochemical studies on type II collageninduced arthritis in rats," Biomedical Research, vol. 3, no. 5, pp. 495-505, 1982.

[39] D. E. Trentham, A. S. Townes, and A. H. Kang, "Autoimmunity to type II collagen: an experimental model of arthritis," Journal of Experimental Medicine, vol. 146, no. 3, pp. 857868, 1977.

[40] D. D. Anthony and T. M. Haqqi, "Collagen-induced arthritis in mice: an animal model to study the pathogenesis of rheumatoid arthritis," Clinical and Experimental Rheumatology, vol. 17, no. 2, pp. 240-244, 1999.

[41] A. B. Blom, P. L. E. M. van Lent, A. E. M. Holthuysen, and W. B. van den Berg, "Immune complexes, but not streptococcal cell walls or zymosan, cause chronic arthritis in mouse strains susceptible for collagen type II auto-immune arthritis," Cytokine, vol. 11, no. 12, pp. 1046-1056, 1999.

[42] R. Holmdahl, T. J. Goldschmidt, S. Kleinau, C. Kvick, and R. Jonsson, "Arthritis induced in rats with adjuvant oil is a genetically restricted, $\alpha \beta$ T-cell dependent autoimmune disease," Immunology, vol. 76, no. 2, pp. 197-202, 1992.

[43] C. Mauri, C. Q. Q. Chu, D. Woodrow, L. Mori, and M. Londei, "Treatment of a newly established transgenic model of chronic arthritis with nondepleting anti-CD4 monoclonal antibody," Journal of Immunology, vol. 159, no. 10, pp. 50325041, 1997.

[44] D. B. Magilavy, "Animal models of chronic inflammatory arthritis," Clinical Orthopaedics and Related Research, no. 259, pp. 38-45, 1990. 
[45] L. J. Crofford and R. L. Wilder, "Arthritis and autoimmunity in animals," in Arthritis and Allied Conditions, W. Koopman, Ed., pp. 565-583, Williams and Wilkins,, Baltimore, Md, USA, 1997.

[46] M. W. Whitehouse, K. J. Orr, F. W. J. Beck, and C. M. Pearson, "Freund's adjuvants: relationship of arthritogenicity and adjuvanticity in rats to vehicle composition," Immunology, vol. 27, no. 2, pp. 311-330, 1974.

[47] J. C. Lorentzen, "Identification of arthritogenic adjuvants of self and foreign origin," Scandinavian Journal of Immunology, vol. 49, no. 1, pp. 45-50, 1999.

[48] S. Yoshino, Y. Murata, and M. Ohsawa, "Successful induction of adjuvant arthritis in mice by treatment with a monoclonal antibody against IL-4," Journal of Immunology, vol. 161, no. 12, pp. 6904-6908, 1998.

[49] J. S. Courtenay, M. J. Dallman, A. D. Dayan, A. Martin, and B. Mosedale, "Immunisation against heterologous type II collagen induces arthritis in mice," Nature, vol. 283, no. 5748, pp. 666-668, 1980.

[50] P. H. Wooley, "Animal models of rheumatoid arthritis," Current Opinion in Rheumatology, vol. 3, no. 3, pp. 407-420, 1991.

[51] E. Šimelyte, M. Rimpiläinen, K. Rantakokko et al., "Tissue distribution and persistence of arthritogenic and nonarthritogenic Eubacterium cell walls," Clinical and Experimental Rheumatology, vol. 17, no. 3, pp. 281-288, 1999.

[52] J. R. Ward and R. S. Jones, "The pathogenesis of mycoplasma (PPLO) arthritis in rats," Arthritis and Rheumatism, vol. 5, pp. 163-175, 1962.

[53] T. J. A. Lehman, J. B. Allen, P. H. Plotz, and R. L. Wilder, "Polyarthritis in rats following the systemic injection of Lactobacillus casei cell walls in aqueous suspension," Arthritis and Rheumatism, vol. 26, no. 10, pp. 1259-1265, 1983.

[54] M. Andreis, P. Stastny, and M. Ziff, "Experimental arthritis produced by injection of mediators of delayed hypersensitivity," Arthritis and Rheumatism, vol. 17, no. 5, pp. 537-551, 1974.

[55] T. D. Cooke and H. E. Jasin, "The pathogenesis of chronic inflammation in experimental antigen-induced arthritis. I. The role of antigen on the local immune response," Arthritis and Rheumatism, vol. 15, no. 4, pp. 327-337, 1972.

[56] L. E. Glynn, "The chronicity of inflammation and its significance in rheumatoid arthritis," Annals of the Rheumatic Diseases, vol. 27, no. 2, pp. 105-121, 1968.

[57] W. B. van den Berg, L. B. A. van de Putte, W. A. Zwarts, and L. A. B. Joosten, "Electrical charge of the antigen determines intraarticular antigen handling and chronicity of arthritis in mice," Journal of Clinical Investigation, vol. 74, no. 5, pp. 1850-1859, 1984.

[58] K. Terato, D. S. Harper, M. M. Griffiths et al., "Collageninduced arthritis in mice: synergistic effect of $E$. coli lipopolysaccharide bypasses epitope specificity in the induction of arthritis with monoclonal antibodies to type II collagen," Autoimmunity, vol. 22, no. 3, pp. 137-147, 1995.

[59] K. S. Nandakumar, L. Svensson, and R. Holmdahl, "Collagen type II-specific monoclonal antibody-induced arthritis in mice: description of the disease and the influence of age, sex, and genes," American Journal of Pathology, vol. 163, no. 5, pp. 1827-1837, 2003.

[60] P. Hutamekalin, T. Saito, K. Yamaki et al., "Collagen antibody-induced arthritis in mice: development of a new arthritogenic 5-clone cocktail of monoclonal anti-type II collagen antibodies," Journal of Immunological Methods, vol. 343, no. 1, pp. 49-55, 2009.
[61] P. A. Monach, D. Mathis, and C. Benoist, "The K/BxN arthritis model," Current Protocols in Immunology, chapter 15, unit 15.22, 2008.

[62] B. Bolon, G. Campagnuolo, L. Zhu, D. Duryea, D. Zack, and U. Feige, "Interleukin- $1 \beta$ and tumor necrosis factor- $\alpha$ produce distinct, time-dependent patterns of acute arthritis in the rat knee," Veterinary Pathology, vol. 41, no. 3, pp. 235243, 2004.

[63] A. M. Malfait, M. Tortorella, J. Thompson et al., "Intraarticular injection of tumor necrosis factor- $\alpha$ in the rat: an acute and reversible in vivo model of cartilage proteoglycan degradation," Osteoarthritis and Cartilage, vol. 17, no. 5, pp. 627-635, 2009.

[64] K. E. Rendt, T. S. Barry, D. M. Jones, C. B. Richter, S. S. McCachren, and B. F. Haynes, "Engraftment of human synovium into severe combined immune deficient mice: migration of human peripheral blood $\mathrm{T}$ cells to engrafted human synovium and to mouse lymph nodes," Journal of Immunology, vol. 151, no. 12, pp. 7324-7336, 1993.

[65] U. Sack, H. Kuhn, J. Ermann et al., "Synovial tissue implants from patients with rheumatoid arthritis cause cartilage destruction in knee joints of SCID.bg mice," Journal of Rheumatology, vol. 21, no. 1, pp. 10-16, 1994.

[66] C. Jorgensen, F. Apparailly, I. Couret, F. Canovas, C. Jacquet, and J. Sany, "Interleukin-4 and interleukin-10 are chondroprotective and decrease mononuclear cell recruitment in human rheumatoid synovium in vivo," Immunology, vol. 93, no. 4, pp. 518-523, 1998.

[67] H. Selye, "On the mechanism through which hydrocortisone affects the resistance of tissues to injury: an experimental study with the granuloma pouch technique," Journal of the American Medical Association, vol. 152, no. 13, pp. 12071213, 1953.

[68] J. C. W. Edwards, A. D. Sedgwick, and D. A. Willoughby, “The formation of a structure with the features of synovial lining by subcutaneous injection of air: an in vivo tissue culture system," Journal of Pathology, vol. 134, no. 2, pp. 147-156, 1981.

[69] A. D. Sedgwick, Y. M. Sin, J. C. W. Edwards, and D. A. Willoughby, "Increased inflammatory reactivity in newly formed lining tissue," Journal of Pathology, vol. 141, no. 4, pp. 483-495, 1983.

[70] A. D. Sedgwick, M. S. Koh, D. A. Willoughby, and M. Pelletier, "Effects of sera and exudate from carrageenantreated rats on two models of acute inflammation," Agents and Actions, vol. 11, no. 5, pp. 477-481, 1981.

[71] I. C. Kowanko, T. P. Gordon, M. A. M. Rozenbilds, P. M. Brooks, and P. J. Roberts-Thomson, "The subcutaneous air pouch model of synovium and the inflammatory response to heat aggregated gammaglobulin," Agents and Actions, vol. 18, no. 3-4, pp. 421-428, 1986.

[72] S. Yoshino, W. J. Cromartie, and J. H. Schwab, "Inflammation induced by bacterial cell wall fragments in the rat air pouch. Comparison of rat strains and measurement of arachidonic acid metabolites," American Journal of Pathology, vol. 121, no. 2, pp. 327-336, 1985.

[73] K. M. K. Bottomley, R. J. Griffiths, T. J. Rising, and A. Steward, "A modified mouse air pouch model for evaluating the effects of compounds on granuloma induced cartilage degradation," British Journal of Pharmacology, vol. 93, no. 3, pp. 627-635, 1988.

[74] Y. M. Sin, A. D. Sedgwick, and D. A. Willoughby, "Studies on the mechanism of cartilage degradation," Journal of Pathology, vol. 142, no. 1, pp. 23-30, 1984. 
[75] V. Taneja, M. Behrens, A. Mangalam, M. M. Griffiths, H. S. Luthra, and C. S. David, "New humanized HLA-DR4transgenic mice that mimic the sex bias of rheumatoid arthritis," Arthritis and Rheumatism, vol. 56, no. 1, pp. 6978, 2007.

[76] A. K. Mangalam, G. Rajagopalan, V. Taneja, and C. S. David, "HLA class II transgenic mice mimic human inflammatory diseases," Advances in Immunology, vol. 97, pp. 65-147, 2008.

[77] J. Keffer, L. Probert, H. Cazlaris et al., "Transgenic mice expressing human tumour necrosis factor: a predictive genetic model of arthritis," EMBO Journal, vol. 10, no. 13, pp. 4025-4031, 1991.

[78] J. M. Milner and T. E. Cawston, "Matrix metalloproteinase knockout studies and the potential use of matrix metalloproteinase inhibitors in the rheumatic diseases," Current Drug Targets, vol. 4, no. 3, pp. 363-375, 2005.

[79] A. S. Korganow, JI. Hong, S. Mangialaio et al., "From systemic T cell self-reactivity to organ-specific autoimmune disease via immunoglobulins," Immunity, vol. 10, no. 4, pp. 451-461, 1999.

[80] Y. Iwakura, "Roles of IL-1 in the development of rheumatoid arthritis: consideration from mouse models," Cytokine and Growth Factor Reviews, vol. 13, no. 4-5, pp. 341-355, 2002.

[81] J. D. Taurog, J. A. Richardson, J. T. Croft et al., "The germfree state prevents development of gut and joint inflammatory disease in HLA-B27 transgenic rats," Journal of Experimental Medicine, vol. 180, no. 6, pp. 2359-2364, 1994.

[82] H. C. Rath, H. H. Herfarth, J. S. Ikeda et al., "Normal luminal bacteria, especially Bacteroides species, mediate chronic colitis, gastritis, and arthritis in HLA-B27/human $\beta 2$ microglobulin transgenic rats," Journal of Clinical Investigation, vol. 98, no. 4, pp. 945-953, 1996.

[83] A. Ebringer and C. Wilson, "HLA molecules, bacteria and autoimmunity," Journal of Medical Microbiology, vol. 49, no. 4, pp. 305-311, 2000.

[84] A. Larbi, T. Fülöp, and G. Pawelec, "Immune receptor signaling, aging and autoimmunity," Advances in Experimental Medicine and Biology, vol. 640, pp. 312-324, 2008.

[85] S. M. Eck, J. S. Blackburn, A. C. Schmucker, P. S. Burrage, and C. E. Brinckerhoff, "Matrix metalloproteinase and G protein coupled receptors: co-conspirators in the pathogenesis of autoimmune disease and cancer," Journal of Autoimmunity, vol. 33, no. 3-4, pp. 214-221, 2009.

[86] A. N. Theofilopoulos and F. J. Dixon, "Etiopathogenesis of murine SLE," Immunological Reviews, vol. 55, no. 1, pp. 179216, 1981.

[87] L. Hang, A. N. Theofilopoulos, and F. J. Dixon, "A spontaneous rheumatoid arthritis-like disease in MRL/1 mice," Journal of Experimental Medicine, vol. 155, no. 6, pp. 16901701, 1982.

[88] V. E. Kelley and J. B. Roths, "Increase in macrophage Ia expression in autoimmune mice: role of the lpr gene," Journal of Immunology, vol. 129, no. 3, pp. 923-925, 1982.

[89] D. B. Magilavy, T. R. Hundley, A. D. Steinberg, and I. M. Katona, "Hepatic reticuloendothelial system activation in autoimmune mice: differences between (NZB x NZW)F and MRL-lpr/lpr strains," Clinical Immunology and Immunopathology, vol. 42, no. 3, pp. 386-398, 1987.

[90] A. Altman, A. N. Theofilopoulos, and R. Weiner, "Analysis of $\mathrm{T}$ cell function in autoimmune murine strains. Defects in production of and responsiveness to interleukin 2," Journal of Experimental Medicine, vol. 154, no. 3, pp. 791-808, 1981.
[91] D. B. Magilavy and J. L. Rothstein, "Spontaneous production of tumor necrosis factor $\alpha$ by Kupffer cells of MRL/lpr mice," Journal of Experimental Medicine, vol. 168, no. 2, pp. 789794, 1988.

[92] R. L. Wilder and J. B. Allen, "Regulation of susceptibility to bacterial cell wall-induced arthritis in rats," Arthritis and Rheumatism, vol. 28, no. 11, pp. 1318-1319, 1985.

[93] M. Stolina, B. Bolon, D. Dwyer et al., "The evolving systemic and local biomarker milieu at different stages of disease progression in rat collagen-induced arthritis," Biomarkers, vol. 13, no. 7-8, pp. 692-712, 2008.

[94] M. Stolina, B. Bolon, S. Middleton et al., "The evolving systemic and local biomarker milieu at different stages of disease progression in rat adjuvant-induced arthritis," Journal of Clinical Immunology, vol. 29, no. 2, pp. 158-174, 2009.

[95] X. Y. Song, L. Zeng, W. Jin, C. M. Pilo, M. E. Frank, and S. M. Wahl, "Suppression of streptococcal cell wall-induced arthritis by human chorionic gonadotropin," Arthritis and Rheumatism, vol. 43, no. 9, pp. 2064-2072, 2000.

[96] D. E. Yocum, J. B. Allen, S. M. Wahl, G. B. Calandra, and R. L. Wilder, "Inhibition by cyclosporin A of streptococcal cell wall-induced arthritis and hepatic granulomas in rats," Arthritis and Rheumatism, vol. 29, no. 2, pp. 262-273, 1986.

[97] E. R. Pettipher, B. Henderson, T. Hardingham, and A. Ratcliffe, "Cartilage proteoglycan depletion in acute and chronic antigen-induced arthritis," Arthritis and Rheumatism, vol. 32, no. 5, pp. 601-607, 1989.

[98] W. J. Cromartie, J. G. Craddock, J. H. Schwab, S. K. Anderle, and C. H. Yang, "Arthritis in rats after systemic injection of streptococcal cells or cell walls," Journal of Experimental Medicine, vol. 146, no. 6, pp. 1585-1602, 1977.

[99] B. Bolon, G. Campagnuolo, and U. Feige, "Duration of bone protection afforded by a single injection of recombinant osteoprotegerin (OPG) in male Lewis rats with adjuvant arthritis," Cellular and Molecular Life Sciences, vol. 59, no. 9, pp. 1569-1576, 2002.

[100] R. L. Clark, M. C. Marr, J. H. Schwab, and W. J. Cromartie, "Microangiographic studies of experimental erosive synovitis in rats," Investigative Radiology, vol. 18, no. 3, pp. 257-263, 1983.

[101] A. Coxon, B. Bolon, J. Estrada et al., "Inhibition of interleukin-1 but not tumor necrosis factor suppresses neovascularization in rat models of corneal angiogenesis and adjuvant arthritis," Arthritis and Rheumatism, vol. 46, no. 10, pp. 2604-2612, 2002.

[102] B. Bolon, S. Morony, Y. Cheng, Y. L. Hu, and U. Feige, "Osteoclast numbers in Lewis rats with adjuvant-induced arthritis: identification of preferred sites and parameters for rapid quantitative analysis," Veterinary Pathology, vol. 41, no. 1, pp. 30-36, 2004.

[103] C. M. Pearson, "Development of arthritis, periarthritis and periostitis in rats given adjuvants," Proceedings of the Society for Experimental Biology and Medicine, vol. 91, no. 1, pp. 95101, 1965.

[104] F. G. Dalldorf, W. J. Cromartie, S. K. Anderle, R. L. Clark, and J. H. Schwab, "The relation of experimental arthritis to the distribution of streptococcal cell wall fragments," American Journal of Pathology, vol. 100, no. 2, pp. 383-402, 1980.

[105] G. Schett, S. Middleton, B. Bolon et al., "Additive boneprotective effects of anabolic treatment when used in conjunction with RANKL and tumor necrosis factor inhibition in two rat arthritis models," Arthritis and Rheumatism, vol. 52, no. 5, pp. 1604-1611, 2005. 
[106] J. D. Taurog, S. S. Kerwar, R. A. McReynolds, G. P. Sandberg, S. L. Leary, and M. L. Mahowald, "Synergy between adjuvant arthritis and collagen-induced arthritis in rats," Journal of Experimental Medicine, vol. 162, no. 3, pp. 962-978, 1985.

[107] D. E. Trentham, R. A. Dynesius, R. E. Rocklin, and J. R. David, "Cellular sensitivity to collagen in rheumatoid arthritis," New England Journal of Medicine, vol. 299, no. 7, pp. 327-332, 1978.

[108] C. M. Pearson and F. D. Wood, "Passive transfer of adjuvant arthritis by lymph node or spleen cells," Journal of Experimental Medicine, vol. 120, no. 4, pp. 547-560, 1964.

[109] J. D. Taurog, G. P. Sandberg, and M. L. Mahowald, "The cellular basis of adjuvant arthritis. II. Characterization of the cells mediating passive transfer," Cellular Immunology, vol. 80, no. 1, pp. 198-204, 1983.

[110] D. E. Trentham, R. A. Dynesius, and J. R. David, "Passive transfer by cells of type II collagen-induced arthritis in rats," Journal of Clinical Investigation, vol. 62, no. 2, pp. 359-366, 1978.

[111] Y. Takai, N. Seki, H. Senoh et al., "Enhanced production of interleukin-6 in mice with type II collagen-induced arthritis," Arthritis and Rheumatism, vol. 32, no. 5, pp. 594-600, 1989.

[112] S. C. Ridge, J. B. Zabriske, A. L. Oronsky, and S. S. Kerwar, "Streptococcal cell wall arthritis: studies with nude (athymic) inbred Lewis rats," Cellular Immunology, vol. 96, no. 1, pp. 231-234, 1985.

[113] Y. Tada, K. Nagasawa, A. Ho et al., "CD28-deficient mice are highly resistant to collagen-induced arthritis," Journal of Immunology, vol. 162, no. 1, pp. 203-208, 1999.

[114] J. M. Stuart, M. A. Cremer, A. S. Townes, and A. H. Kang, "Type II collagen-induced arthritis in rats. Passive transfer with serum and evidence that IgG anticollagen antibodies can cause arthritis," Journal of Experimental Medicine, vol. 155, no. 1, pp. 1-16, 1982.

[115] M. Ehinger, M. Vestberg, A. C. M. Johansson, M. Johannesson, A. Svensson, and R. Holmdahl, "Influence of CD4 or CD8 deficiency on collagen-induced arthritis," Immunology, vol. 103, no. 3, pp. 291-300, 2001.

[116] T. F. Kresina, I. A. Rosner, V. M. Goldberg, and R. W. Moskowitz, "Immunoglobulin G-induced experimental chronic immune synovitis: cell-mediated immunity to native interstitial collagen molecules and their constituent polypeptide chains," Cellular Immunology, vol. 87, no. 2, pp. 504-516, 1984.

[117] T. F. Kresina, I. A. Rosner, V. M. Goldberg, and R. W. Moskowitz, "Fine specificity of serum anticollagen molecules in experimental immune synovitis," Annals of the Rheumatic Diseases, vol. 44, no. 5, pp. 328-335, 1985.

[118] H. K. Beard, R. Ryvar, J. Skingle, and C. L. Greenbury, "Anti-collagen antibodies in sera from rheumatoid arthritis patients," Journal of Clinical Pathology, vol. 33, no. 11, pp. 1077-1081, 1980.

[119] P. H. Wooley, H. S. Luthra, J. D. O'Duffy, T. W. Bunch, S. B. Moore, and J. M. Stuart, "Anti-type II collagen antibodies in rheumatoid arthritis. The influence of HLA phenotype," Tissue Antigens, vol. 23, no. 5, pp. 263-269, 1984.

[120] L. Svensson, J. Jirholt, R. Holmdahl, and L. Jansson, "B cell-deficient mice do not develop type II collagen-induced arthritis (CIA)," Clinical and Experimental Immunology, vol. 111, no. 3, pp. 521-526, 1998.

[121] R. Janis and D. Hamerman, "Articular cartilage changes in early arthritis," Bulletin of the Hospital for Joint Diseases, vol. 30, no. 2, pp. 136-152, 1969.
[122] J. R. Hollister and M. Mannik, "Antigen retention in joint tissues in antigen induced synovitis," Clinical and Experimental Immunology, vol. 16, no. 4, pp. 615-627, 1974.

[123] S. S. Kerwar, M. E. Englert, R. A. McReynolds et al., “Type II collagen-induced arthritis. Studies with purified anticollagen immunoglobulin," Arthritis and Rheumatism, vol. 26, no. 9, pp. 1120-1131, 1983.

[124] Z. Wu, K. Toh, K. Nagata, T. Kukita, and T. Iijima, "Effect of the resection of the sciatic nerve on the Th1/Th2 balance in the synovia of the ankle joint of adjuvant arthritic rats," Histochemistry and Cell Biology, vol. 121, no. 2, pp. 141-147, 2004.

[125] E. Lubberts, "Th17 cytokines and arthritis," Seminars in Immunopathology, vol. 32, no. 1, pp. 43-53, 2010.

[126] T. R. Mosmann, H. Cherwinski, M. W. Bond, M. A. Giedlin, and R. L. Coffman, "Two types of murine helper T cell clone. I. Definition according to profiles of lymphokine activities and secreted proteins," Journal of Immunology, vol. 136, no. 7, pp. 2348-2357, 1986.

[127] M. Feldmann, F. M. Brennan, and R. N. Maini, "Role of cytokines in rheumatoid arthritis," Annual Review of Immunology, vol. 14, pp. 397-440, 1996.

[128] W. B. van den Berg, "Joint inflammation and cartilage destruction may occur uncoupled," Springer Seminars in Immunopathology, vol. 20, no. 1-2, pp. 149-164, 1998.

[129] N. C. Walsh and E. M. Gravallese, "Bone remodeling in rheumatic disease: a question of balance," Immunological Reviews, vol. 233, no. 1, pp. 301-312, 2010.

[130] F. M. Brennan and I. B. McInnes, "Evidence that cytokines play a role in rheumatoid arthritis," Journal of Clinical Investigation, vol. 118, no. 11, pp. 3537-3545, 2008.

[131] S. C. Ridge, J. B. Zabriskie, H. Osawa, T. Diamantstein, A. L. Oronsky, and S. S. Kerwar, "Administration of group A streptococcal cell walls to rats induces an interleukin 2 deficiency," Journal of Experimental Medicine, vol. 164, no. 1, pp. 327-332, 1986.

[132] W. P. Arend and J. M. Dayer, "Inhibition of the production and effects of interleukin- 1 and tumor necrosis factor $\alpha$ in rheumatoid arthritis," Arthritis and Rheumatism, vol. 38, no. 2, pp. 151-160, 1995.

[133] F. M. Brennan, M. Field, C. Q. Chu, M. Feldmann, and R. N. Maini, "Cytokine expression in rheumatoid arthritis," British Journal of Rheumatology, vol. 30, pp. 76-80, 1991.

[134] C. Keller, A. Webb, and J. Davis, "Cytokines in the seronegative spondyloarthropathies and their modification by TNF blockade: a brief report and literature review," Annals of the Rheumatic Diseases, vol. 62, no. 12, pp. 1128-1132, 2003.

[135] S. Roberts and R. C. Butler, "Inflammatory mediators as potential therapeutic targets in the spine," Current Drug Targets, vol. 4, no. 2, pp. 257-266, 2005.

[136] M. Stolina, G. Schett, D. Dwyer et al., "RANKL inhibition by osteoprotegerin prevents bone loss without affecting local or systemic inflammation parameters in two rat arthritis models: comparison with anti-TNF $\alpha$ or anti-IL-1 therapies," Biomarkers, vol. 11, no. 6, p. R187, 2009.

[137] F. M. Brennan, R. N. Maini, and M. Feldmann, "Role of proinflammatory cytokines in rheumatoid arthritis," Springer Seminars in Immunopathology, vol. 20, no. 1-2, pp. 133-147, 1998.

[138] W. B. van den Berg and P. Miossec, "IL-17 as a future therapeutic target for rheumatoid arthritis," Nature Reviews Rheumatology, vol. 5, no. 10, pp. 549-553, 2009. 
[139] S. L. Gaffen, "Biology of recently discovered cytokines: interleukin-17-a unique inflammatory cytokine with roles in bone biology and arthritis," Arthritis Research and Therapy, vol. 6, no. 6, pp. 240-247, 2004.

[140] I. B. McInnes and J. A. Gracie, "Targeting cytokines beyond tumor necrosis factor- $\alpha$ and interleukin- 1 in rheumatoid arthritis," Current Rheumatology Reports, vol. 6, no. 5, pp. 336-342, 2004.

[141] K. A. Bush, K. M. Farmer, J. S. Walker, and B. W. Kirkham, "Reduction of joint inflammation and bone erosion in rat adjuvant arthritis by treatment with interleukin-17 receptor IgG1 Fc fusion protein," Arthritis and Rheumatism, vol. 46, no. 3, pp. 802-805, 2002.

[142] B. J. Rollins, "Monocyte chemoattractant protein 1: a potential regulator of monocyte recruitment in inflammatory disease," Molecular Medicine Today, vol. 2, no. 5, pp. 198-204, 1996.

[143] L. Punzi, L. Calo, and M. Plebani, "Clinical significance of cytokine determination in synovial fluid," Critical Reviews in Clinical Laboratory Sciences, vol. 39, no. 1, pp. 63-88, 2002.

[144] N. Maruotti, F. P. Cantatore, E. Crivellato, A. Vacca, and D. Ribatti, "Angiogenesis in rheumatoid arthritis," Histology and Histopathology, vol. 21, no. 5, pp. 557-566, 2006.

[145] M. Cutolo, B. Villaggio, L. Foppiani et al., "The hypothalamic-pituitary-adrenal and gonadal axes in rheumatoid arthritis," Annals of the New York Academy of Sciences, vol. 917, pp. 835-843, 2000.

[146] R. L. Wilder, "Hormones and autoimmunity: animal models of arthritis," Bailliere's Clinical Rheumatology, vol. 10, no. 2, pp. 259-271, 1996.

[147] J. B. Allen, D. Blatter, G. B. Calandra, and R. L. Wilder, "Sex hormonal effects on the severity of streptococcal cell wallinduced polyarthritis in the rat," Arthritis and Rheumatism, vol. 26, no. 4, pp. 560-563, 1983.

[148] E. M. Sternberg, J. M. Hill, G. P. Chrousos et al., "Inflammatory mediator-induced hypothalamic-pituitary-adrenal axis activation is defective in streptococcal cell wall arthritissusceptible Lewis rats," Proceedings of the National Academy of Sciences of the United States of America, vol. 86, no. 7, pp. 2374-2378, 1989.

[149] M. Cutolo and R. H. Straub, "Stress as a risk factor in the pathogenesis of rheumatoid arthritis," NeuroImmunomodulation, vol. 13, no. 5-6, pp. 277-282, 2006.

[150] M. P. Rogers, D. E. Trentham, W. J. McCune et al., "Abrogation of type II collagen-induced arthritis in rats by psychological stress," Transactions of the Association of American Physicians, vol. 92, pp. 218-228, 1979.

[151] L. Probert, D. Plows, G. Kontogeorgos, and G. Kollias, "The type I interleukin-1 receptor acts in series with tumor necrosis factor (TNF) to induce arthritis in TNF-transgenic mice," European Journal of Immunology, vol. 25, no. 6, pp. 1794-1797, 1995.

[152] G. Schett, K. Redlich, S. Hayer et al., "Osteoprotegerin protects against generalized bone loss in tumor necrosis factor-transgenic mice," Arthritis and Rheumatism, vol. 48, no. 7, pp. 2042-2051, 2003.

[153] E. Brahn, "Animal models of rheumatoid arthritis. Clues to etiology and treatment," Clinical Orthopaedics and Related Research, no. 265, pp. 42-53, 1991.

[154] X. Y. Song, M. Gu, W. W. Jin, D. M. Klinman, and S. M. Wahl, "Plasmid DNA encoding transforming growth factor$\beta 1$ suppresses chronic disease in a streptococcal cell wallinduced arthritis model," Journal of Clinical Investigation, vol. 101, no. 12, pp. 2615-2621, 1998.
[155] B. Bolon, V. Shalhoub, P. J. Kostenuik et al., "Osteoprotegerin, an endogenous antiosteoclast factor for protecting bone in rheumatoid arthritis," Arthritis and Rheumatism, vol. 46, no. 12, pp. 3121-3135, 2002.

[156] Y. Kung, U. Felge, I. Sarosi et al., "Activated T cells regulate bone loss and joint destruction in adjuvant arthritis through osteoprotegerin ligand," Nature, vol. 402, no. 6759, pp. 304309, 1999.

[157] S. W. Lee, J. M. Greve, D. Leaffer et al., "Early findings of small-animal MRI and small-animal computed tomography correlate with histological changes in a rat model of rheumatoid arthritis," NMR in Biomedicine, vol. 21, no. 5, pp. 527536, 2008.

[158] M. Noguchi, A. Kimoto, M. Sasamata, and K. Miyata, "Micro-CT imaging analysis for the effect of celecoxib, a cyclooxygenase-2 inhibitor, on inflammatory bone destruction in adjuvant arthritis rats," Journal of Bone and Mineral Metabolism, vol. 26, no. 5, pp. 461-468, 2008.

[159] L. Svensson, K. S. Nandakumar, A. Johansson, L. Jansson, and R. Holmdahl, "IL-4-deficient mice develop less acute but more chronic relapsing collagen-induced arthritis," European Journal of Immunology, vol. 32, no. 10, pp. 2944-2953, 2002.

[160] O. Kohashi, J. Kuwata, K. Umehara, F. Uemura, T. Takahashi, and A. Ozawa, "Susceptibility to adjuvant-induced arthritis among germfree, specific-pathogen-free, and conventional rats," Infection and Immunity, vol. 26, no. 3, pp. 791-794, 1979.

[161] Z. Szekanecz, M. M. Halloran, M. V. Volin et al., "Temporal expression of inflammatory cytokines and chemokines in rat adjuvant-induced arthritis," Arthritis and Rheumatism, vol. 43, no. 6, pp. 1266-1277, 2000.

[162] N. Kaibara, T. Hotokebuchi, K. Takagishi, and I. Katsuki, "Paradoxical effects of cyclosporin A on collagen arthritis in rats," Journal of Experimental Medicine, vol. 158, no. 6, pp. 2007-3015, 1983. 


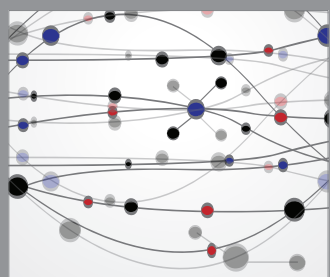

The Scientific World Journal
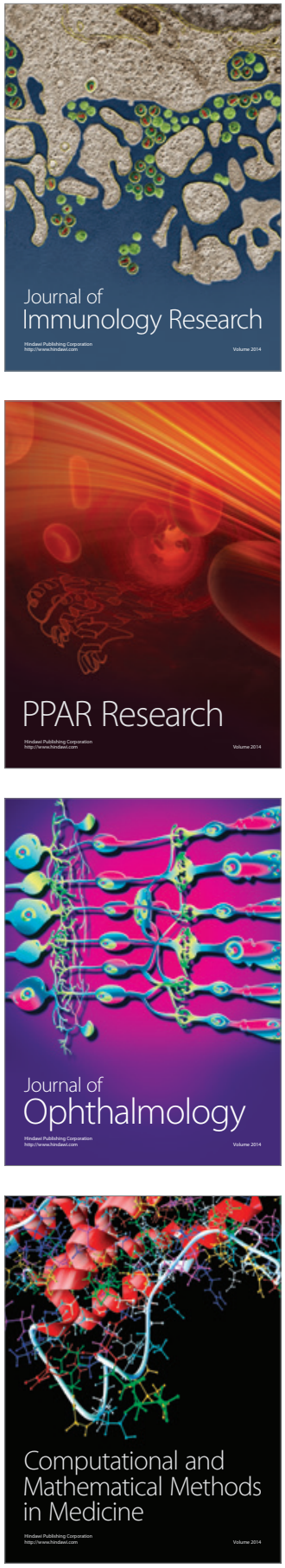

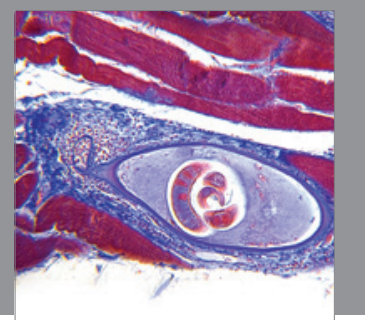

Gastroenterology

Research and Practice
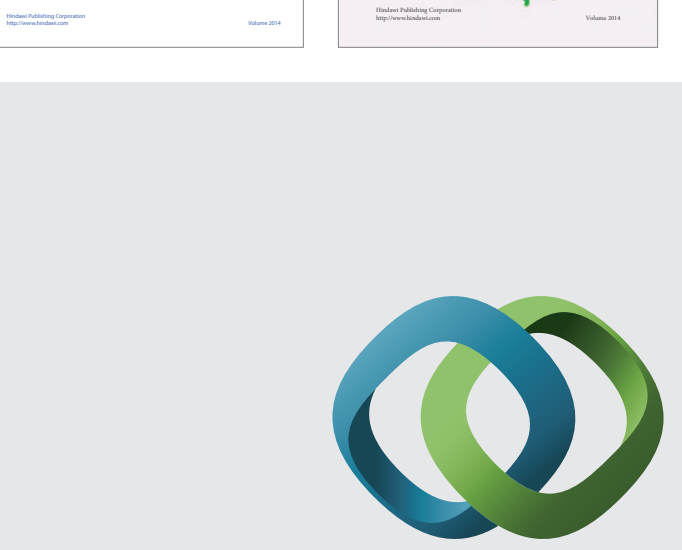

\section{Hindawi}

Submit your manuscripts at

http://www.hindawi.com
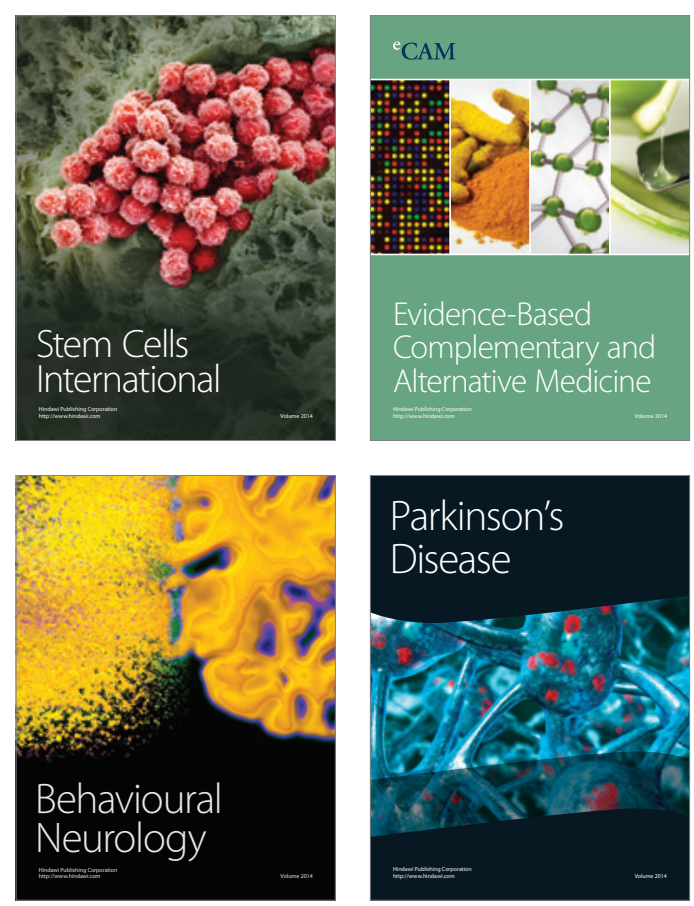

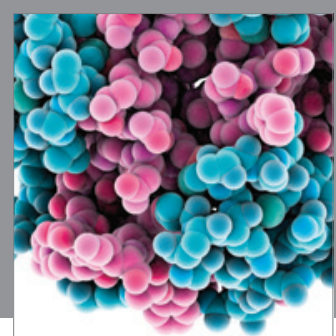

Journal of
Diabetes Research

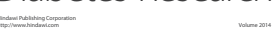

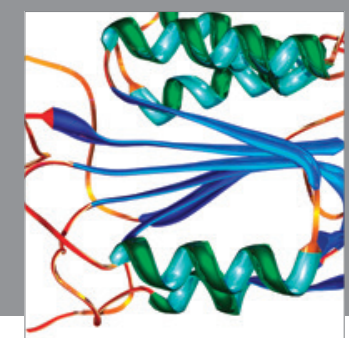

Disease Markers
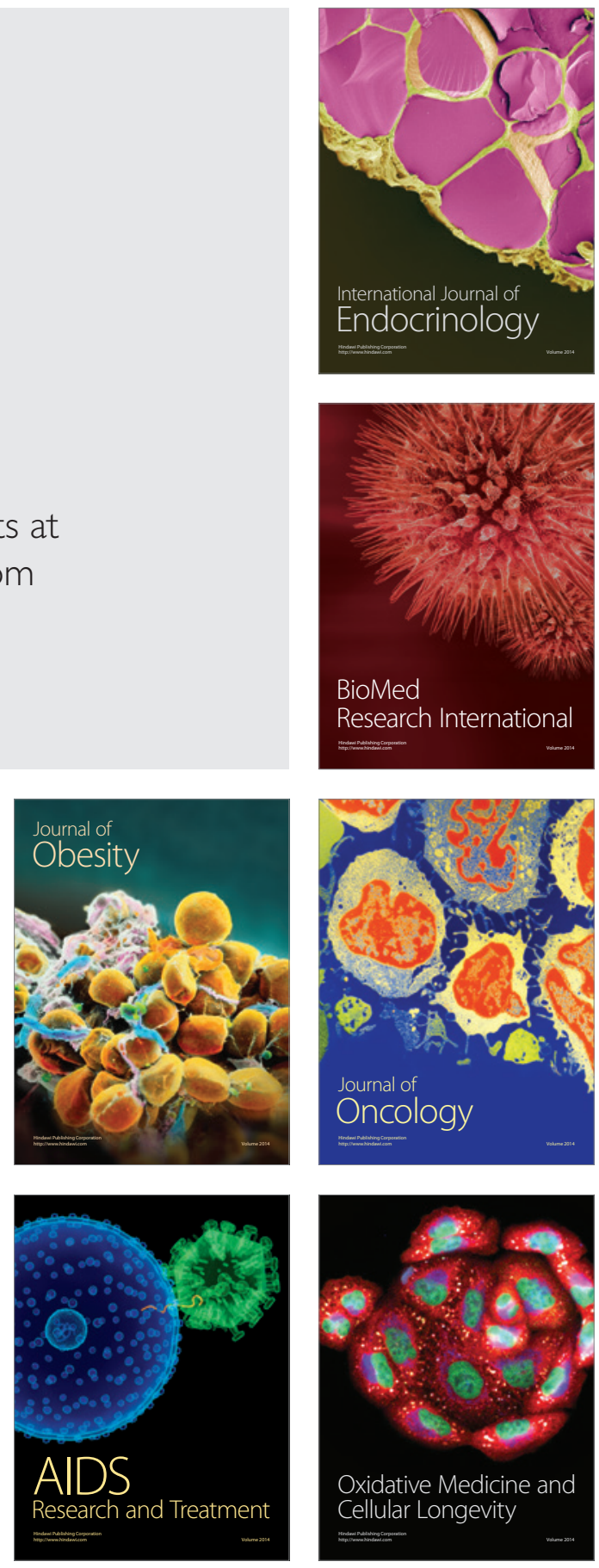